\title{
Ankyrin-R regulates fast-spiking interneuron excitability through perineuronal nets and
} Kv3.1b K+ channels

Sharon R. Stevens ${ }^{1}$, Colleen M. Longley ${ }^{2,3}$, Yuki Ogawa ${ }^{1}$, Lindsay H. Teliska ${ }^{1}$,

5 Anithachristy S. Arumanayagam ${ }^{4}$, Supna Nair ${ }^{5}$, Juan A. Oses-Prieto ${ }^{5}$, Alma L. Burlingame ${ }^{5}$,

6 Matthew D. Cykowski ${ }^{4}$, Mingshan Xue ${ }^{1,2,3,6}$, and Matthew N. Rasband ${ }^{1,2}$

${ }^{1}$ Department of Neuroscience, ${ }^{2}$ Program in Developmental Biology, ${ }^{6}$ Department of Molecular and Human Genetics, Baylor College of Medicine, Houston, TX, USA.

${ }^{3}$ The Cain Foundation Laboratories, Jan and Dan Duncan Neurological Research Institute at Texas Children's Hospital, Houston, TX, USA.

${ }^{4}$ Department of Pathology and Genomic Medicine, Houston Methodist Hospital, Houston, TX, USA.

${ }^{5}$ Department of Pharmaceutical Chemistry, University of California San Francisco, San Francisco, CA, USA.

\section{Address correspondence to:}

Matthew N. Rasband, PhD

20 Department of Neuroscience

21 Baylor College of Medicine

22 One Baylor Plaza

23 Houston, Texas 77030

24 Tel: 713-798-4494

25 Fax: 713-798-3946

26 E-mail: rasband@bcm.edu

Running title: AnkR in the nervous system

Word count: Abstract, 146; Introduction, results, and discussion combined, 5431.

Figures, 7. Supplemental Figures, 6. Supplemental Table, 1. Supplemental Movies, 2. 
ABSTRACT

Neuronal ankyrins cluster and link membrane proteins to the actin and spectrin-based

38 cytoskeleton. Among the three vertebrate ankyrins, little is known about neuronal Ankyrin-R

39 (AnkR). We report AnkR is highly enriched in $\mathrm{Pv}^{+}$fast-spiking interneurons in mouse and

40 human. We identify AnkR-associated protein complexes including cytoskeletal proteins, cell

41 adhesion molecules (CAMs), and perineuronal nets (PNNs). We show that loss of AnkR from

42 forebrain interneurons reduces and disrupts PNNs, decreases anxiety-like behaviors, and

43 changes the intrinsic excitability and firing properties of $\mathrm{Pv}^{+}$fast-spiking interneurons. These

44 changes are accompanied by a dramatic reduction in $\mathrm{Kv} 3.1 \mathrm{~b} \mathrm{~K}^{+}$channels. We identify a novel

45 AnkR-binding motif in Kv3.1b, and show that AnkR is both necessary and sufficient for Kv3.1b

46 membrane localization in interneurons and at nodes of Ranvier. Thus, AnkR regulates $\mathrm{Pv}^{+}$fast-

47 spiking interneuron function by organizing ion channels, CAMs, and PNNs, and linking these to

48 the underlying $\beta 1$ spectrin-based cytoskeleton. 


\section{INTRODUCTION}

Ion channels and cell adhesion molecules (CAMs) are frequently recruited to, stabilized, and maintained at specific neuronal membrane domains by scaffolding proteins. The ankyrin scaffolding proteins, consisting of Ankyrin-R, -B, and -G (AnkR, AnkB, and AnkG, respectively),

53 are the primary link between the submembranous spectrin-based cytoskeleton and the cytoplasmic domains of many transmembrane proteins (Michaely and Bennett, 1995; Sedgwick and Smerdon, 1999). For example, AnkG links $\mathrm{Na}^{+}$and $\mathrm{K}^{+}$channels, and the CAM neurofascin 186 (NF186) at axon initial segments (AIS) and nodes of Ranvier to the underlying $\beta 4$ spectrin and actin-based cytoskeleton. The clustering of channels at the AIS and nodes facilitates fast and efficient action potential propagation (Dzhashiashvili et al., 2007; Zhou et al., 1998). Similarly, AnkB stabilizes $\mathrm{Na}^{+}$channels and L1CAM family membrane proteins in unmyelinated axons and at paranodal junctions of myelinated axons by linking these membrane proteins to $\beta 2$ spectrin (Chang et al., 2014; Scotland et al., 1998; Susuki et al., 2018). However, little is known about the function of AnkR in the nervous system. Instead, AnkR has mostly been studied in red blood cells where it maintains the cell's structural integrity via its link between $\beta 1$ spectrin and the cytoplasmic domain of the anion exchanger Band 3 (Bennett and Stenbuck, 1979). Loss of AnkR results in fragile erythrocyte membranes and hemolytic anemia (Lux et al., 1990). Intriguingly, case studies of patients with hereditary spherocytic anemia, caused by mutations in AnkR, report various neurological disturbances (Coetzer et al., 1988; McCann and Jacob, 1976; Miya et al., 2012), and a number of recent epigenome-wide association studies in Alzheimer's disease (AD) have consistently found neuropathology-associated DNA hypermethylation of $A N K 1$ (ANK1 is the gene encoding AnkR) (De Jager et al., 2014; Gasparoni et al., 2018; Higham et al., 2019; Lunnon et al., 2014; Smith et al., 2019a; Smith et al., 2019b).

72 Additionally, AnkR can substitute for AnkG to cluster $\mathrm{Na}^{+}$channels at nodes of Ranvier (Ho et al., 73 2014) but not AIS (Liu et al., 2020a). Thus, AnkR may play important, but as yet undefined, roles in nervous system function in both the healthy and diseased brain. assembles and maintains a complex extracellular matrix (ECM) consisting of chondroitin sulfate proteoglycans (CSPGs) and other ECM proteins that surround AIS and nodes of Ranvier (Amor 
et al., 2017; Hedstrom et al., 2007; Susuki et al., 2013). Thus, ankyrins may function generally to link ECMs to the cytoskeleton through their membrane receptors. One highly condensed and specialized ECM in the nervous system is the perineuronal net (PNN). PNNs surround synaptic

81 innervations and are thought to be important to maintain the balance of excitation and

82 inhibition (Carceller et al., 2020). The majority of PNNs surround the soma and proximal 83 dendrites of fast-spiking parvalbumin-positive $\left(\mathrm{Pv}^{+}\right)$inhibitory interneurons and have a CSPG 84 composition similar to the perinodal and AIS ECM (Fawcett et al., 2019). However, how PNNs

85 themselves are assembled, maintained, and restricted to specific domains and neuronal 86 subtypes, is unknown.

Here, we show the loss of AnkR from GABAergic forebrain neurons results in a reduction and altered structure of PNNs, a reduction in anxiety-like behaviors, and altered intrinsic excitability and firing properties of $\mathrm{PNN}^{+}$fast-spiking interneurons. We identify AnkRinteracting adhesion molecules that may tether PNNs to the spectrin cytoskeleton. Importantly, the altered excitability reflects the loss of Kv3.1b $\mathrm{K}^{+}$channels. We identify the motif in Kv3.1b necessary for its interaction with AnkR. We show AnkR is both necessary and sufficient for the recruitment and clustering of $\mathrm{Kv} 3.1 \mathrm{~b} \mathrm{~K} \mathrm{~K}^{+}$channels in the neuronal membrane.

\section{RESULTS}

\section{AnkR is highly enriched in $\mathrm{Pv}^{+}$inhibitory interneurons}

To determine where AnkR is located, we immunostained mouse forebrain using antibodies against AnkR. We found that AnkR is highly enriched in the soma and proximal dendrites of a subset of neurons sparsely distributed throughout the cortex and hippocampus (Fig. 1A). Immunoblotting of brain homogenates shows AnkR protein in the brain increases during early postnatal development, peaking by postnatal day 30 (Fig. 1B). The sparse

103 interneurons. Indeed, immunostaining with antibodies against parvalbumin (Pv), a marker of 104 fast-spiking interneurons (Fig. 1C, D), shows $>90 \%$ of $\mathrm{Pv}^{+}$cells in postnatal day 56 (P56) cortex 105 and hippocampus have high levels of $A n k R$, while only $~ 70 \%$ of $A n k R^{+}$cells in cortex and 
staining was identified in laminae II-VI in human cortical biopsy samples. Labeling was strong and membranous and was most intense in larger neurons of laminae III and V (Fig. 1E). AnkR staining intensity in large neurons of lamina III and V was similar to staining intensity of erythrocytes (not shown). Furthermore, AnkR labeling was only identified in a subset of

111 neurons in human cortex and staining was not present in endothelial cells or glia. A subset of

$112 \mathrm{AnkR}^{+}$neurons in laminae III and V co-expressed PV in the neuronal cytoplasm (Fig. 1E),

113 although, as in mice, the total number of $\mathrm{AnkR}^{+}$positive neurons exceed the number of $\mathrm{Pv}^{+}$

114 cells. These results expand on those previously reported in rat neocortex (Wintergerst et al., 115 1996).

To determine the role of neuronal AnkR and confirm its high expression in interneurons, we constructed a floxed allele for Ank1 (Ank1 ${ }^{\mathrm{F} / F}$; Fig. 1F); this new model allows for an

118 exploration of AnkR function in the brain while avoiding the confound of anemia due to loss of 119 AnkR from red blood cells. We removed AnkR from the nervous system using Nestin-Cre mice $120\left(\right.$ Ank1 ${ }^{F / F} ;$ Nes-Cre $)$, and from GABAergic forebrain interneurons using D/x5/6-Cre mice $121\left(A n k 1^{F / F} ; D / x 5 / 6-C r e\right)$. We confirmed the efficient loss of AnkR after recombination by 122 immunoblot of $A n k 1^{F / F}$;Nes-Cre brain homogenates (Fig. 1G). Moreover, immunostaining of 123 forebrain sections from both $A n k 1^{F / F} ;$ Nes-Cre and $A n k 1^{F / F} ; D / \times 5 / 6-C r e$ showed efficient and 124 selective loss of AnkR in neurons; AnkR expression in erythrocytes was unaffected 125 (Supplemental Fig. 1A). These results also highlight the specificity of our antibodies. 126 Additionally, hemoglobin levels in Ank1 ${ }^{F / F} ; N e s-C r e$ and $A n k 1^{F / F} ; D / x 5 / 6-C r e$ mice were normal 127 (data not shown). Although most $\mathrm{Pv}^{+}$cells are $\mathrm{AnkR}^{+}$(Fig. 1C, D) there is a subpopulation of $128 \mathrm{AnkR}^{+}$neurons that are not $\mathrm{Pv}^{+}$; these cells are most likely another subtype of GABAergic 129 neuron since neurons with high levels of AnkR immunoreactivity in cortical and hippocampal 130 neurons were not detected in $A n k 1^{F / F} ; D / \times 5 / 6$-Cre mice (Supplemental Fig. 1A). Interestingly, 131 and in contrast to the rescue of AnkG by AnkR at nodes of Ranvier(Ho et al., 2014), we found no 132 evidence for reciprocal compensation by AnkG in AnkR-deficient neurons. AnkG in $\mathrm{Pv}^{+}$neurons 133 in cortex remained highly restricted to the AIS and nodes in all genotypes analyzed 134 (Supplemental Fig. 1B and data not shown). Together, these results show that AnkR is 135 abundantly expressed in $\mathrm{Pv}^{+}$interneurons of the forebrain, that its localization is distinct from 
that of AnkB and AnkG, and that we have generated a floxed Ank1 allele that allows for celltype specific deletion in the nervous system.

\section{Elucidating the AnkR interactome}

What functions does AnkR have in GABAergic forebrain interneurons? To begin to answer this question we determined AnkR's interactome. Since AnkR and $\beta 1$ spectrin are binding partners in erythrocytes and can function together at nodes of Ranvier to stabilize $\mathrm{Na}^{+}$ channels (Liu et al., 2020b), we first showed that AnkR and $\beta 1$ spectrin also form a protein complex in $\mathrm{Pv}^{+}$interneurons. Immunostaining showed that $\beta 1$ spectrin is highly expressed and

145 colocalizes with AnkR in forebrain interneurons (Fig. 2A). Furthermore, $\beta 1$ spectrin and AnkR reciprocally co-immunoprecipitate each other (Fig. 2B). Immunoblots of $A n k 1^{\mathrm{F} / F}$;Nes-Cre mouse brain homogenates show that $\beta 1$ spectrin protein levels are significantly reduced in the absence of AnkR compared to control mice (Fig. 2C). Similarly, immunostaining of cortex and hippocampus from Ank $1^{F / F}$;Nes-Cre mice showed remarkably reduced $\beta 1$ spectrin immunofluorescence compared to control mice (Supplemental Fig. 2A, B). Together, these results show that AnkR interacts with and maintains $\beta 1$ spectrin in $\mathrm{Pv}^{+}$forebrain interneurons. immunoprecipitations (IPs) in biological triplicate from whole $A n k 1^{F / F}$ mouse brain lysates. These yielded 3241 unique proteins with at least one peptide spectral match (PSM) in each sample. We further narrowed the number of potential AnkR-binding proteins by setting an arbitrary threshold of $\geq 10$ mean PSMs found in the IPs. As a second, orthogonal approach, we performed differential proteomics and mass spectrometry using wildtype (Ank1 $1^{+/+}$or WT) and AnkR-deficient (Ank1 pale/pale or AnkR-KO)(Ho et al., 2014) hindbrain homogenates

160 (Supplemental Fig. 2C). We used AnkR-KO mice rather than Ank1 ${ }^{\mathrm{F} / F} ; \mathrm{Nes}$-Cre mice to avoid 161 confounds due to incomplete recombination or contributions from cells still expressing AnkR.

162 Mass spectrometry yielded 2465 unique proteins, of which 986 were reduced in AnkR-KO mice 163 compared to WT. Since ankyrins function as scaffolds that stabilize and retain membrane proteins, we reasoned that loss of AnkR might result in increased turnover and lower amounts 
of AnkR-interacting proteins. Therefore, we focused only on those proteins that had fewer PSMs in the AnkR-KO compared to WT. To further refine our analysis, we set an arbitrary threshold such that potential AnkR-interacting proteins must have $\geq 20 \%$ reduction in PSMs, with $\geq 5$ PSMs found in WT mice and a $\geq 3$ PSMs difference between WT and AnkR-KO. Combining the two data sets revealed 72 potential AnkR-interacting proteins (Supplemental Fig. 2C).

We sorted these 72 proteins into functional categories and plotted them using

172 concentric rings to indicate the percent reduction in AnkR-KO mice, with circle size representing

173 the mean number of PSMs in the IPs (Fig. 2D). Among the proteins enriched and passing our

174 stringent filtering criteria, we found cytoskeletal, membrane, signaling, and ECM proteins.

175 Surprisingly, although AnkR is a cytoplasmic scaffolding protein, the ECM proteins TenascinC 176 (TnC), TenascinR (TnR), Brevican (Bcan) and Versican (Vcan) were all identified in the AnkR IPs 177 and also enriched in WT compared to AnkR-KO. We previously reported that AnkG, through the 178 CAM NF186, interacts with and recruits the CSPGs Bcan and Vcan to AIS and nodes of Ranvier 179 (Hedstrom et al., 2008; Susuki et al., 2013). TnR is also found at nodes and binds to Vcan and 180 Bcan (Bekku et al., 2009). Immunostaining of cortex revealed that antibodies against TnR and 181 Bcan strongly label AnkR+ neurons (Figs. 2E, F); Vcan immunoreactivity was not restricted to $182 \mathrm{AnkR}^{+}$neurons and was more widely distributed (Fig. 2H). TnR, Bcan and Vcan are well known components of PNNs (Fawcett et al., 2019; Wintergerst et al., 1996). Immunostaining for the

184 CSPG and PNN protein Aggrecan (Acan) (Carulli et al., 2007; Rowlands et al., 2018) also showed strong colocalization with AnkR (Fig. 2G); although Acan was detected by mass spectrometry, it 186 did not pass our stringent filtering. In addition to antibodies against Bcan, TnR, and Acan, PNNs can also be detected using the fluorescently-labeled Wisteria Floribunda (WFA) lectin (Bruckner 188 et al., 1993), which binds to $N$-acetyl-D-glucosamine at the ends of chondroitin sulfate chains. 189 Co-staining of WFA and AnkR shows that AnkR ${ }^{+}$neurons are surrounded by WFA-labeled PNNs 190 (Fig. 2I).

How can AnkR, an intracellular scaffolding protein, interact with extracellular PNNs? We 192 reasoned this could occur through CAMs that bridge AnkR and PNNs. Our list of potential AnkR193 binding CAMs included two strong candidates: NrCAM and PlexinA4. NrCAM is a member of 
the L1 family of CAMs with known ankyrin-binding activity (Davis and Bennett, 1994). However, NrCAM can also be shed from the cell surface and incorporated into the ECM surrounding nodes of Ranvier through direct binding to NF186 (Susuki et al., 2013). Thus, NrCAM can

197 function both as a membrane receptor and as a component of the perinodal ECM.

198 Immunostaining for NrCAM showed strong colocalization with both AnkR ${ }^{+}$and WFA neurons in caudoputamen (Fig. 2J and Supplemental Fig. 2G), but less robust colocalization in hippocampus and cortex (Supplemental Figs. 2D-F). These results suggest AnkR may function

201 together with NrCAM in a subset of GABAergic neurons and emphasizes the diversity of PNNs 202 and their interacting proteins. Somatodendritic, but not AIS, NrCAM immunoreactivity was 203 dramatically reduced in Ank1 ${ }^{F / F}$;Nes-Cre mouse brain (Fig. 2J). Furthermore, NrCAM and AnkR 204 reciprocally co-immunoprecipitate each other, while the axonal membrane protein Caspr, 205 normally found at paranodal junctions of myelinated axons, does not (Fig. 2K). These results 206 support recent work exploring the molecular heterogeneity of PNNs and suggests another 207 potential PNN subtype involving a unique CAM membrane receptor (Irvine and Kwok, 2018; 208 Yamada and Jinno, 2017).

PlexinA4 functions together with Neuropilin-1 (Nrp1) as a receptor for semaphorin 210 signaling (Nakamura et al., 2000). Sema3A is a component of the PNNs surrounding $\mathrm{Pv}^{+}$ 211 interneurons (Kwok et al., 2011); moreover, enzymatic or genetic disruption of PNNs reduces

212 Sema3A (de Winter et al., 2016). PlexinA4 and Nrp1 are widely expressed throughout the 213 nervous system. Although immunostaining did not reveal any specific enrichment for PlexinA4 214 in AnkR ${ }^{+}$interneurons, immunostaining for Nrp1 showed strong enrichment in AnkR ${ }^{+}$neurons in 215 deep cerebellar nuclei (Supplemental Fig. 2I). Nevertheless, we found that PlexinA4 and Nrp1 216 co-immunoprecipitated with AnkR from brain homogenates (Fig. 2L). Together, our proteomic

217 studies show that AnkR co-localizes with multiple PNN proteins and may indirectly interact with 218 PNNs through the membrane receptors NrCAM and PlexinA4. Other membrane proteins 219 identified in our proteomics, but not analyzed here, may also function to link PNNs to AnkR.

220 Based on these proteomic, biochemical, and immunostaining results, we focused on the 221 relationship between AnkR and PNNs. 
AnkR is required to maintain PNN density and structure

To determine if AnkR contributes to the formation, maintenance, and structure of PNNs,

225 we used WFA to label PNNs in cortex and hippocampus of one-month-old Ank1F/F,

$226 A n k 1^{+/+} ; D l \times 5 / 6-C r e$, and $A n k 1^{F / F} ; D / \times 5 / 6-C r e$ mice (Fig. 3A). At this age, we found little difference

227 in the number of $\mathrm{WFA}^{+} / \mathrm{Pv}^{+}, \mathrm{WFA}^{-} / \mathrm{Pv}^{+}$, or $\mathrm{WFA}^{+} / \mathrm{Pv}^{-}$neurons per unit area (UA) in either

228 hippocampus or cortex (Fig. 3B). However, when we measured the fluorescence intensity of

229 WFA, we found a significant reduction in both cortex and hippocampus in Ank1 $1^{F / F} ; D / \times 5 / 6-C r e$

230 mice compared to floxed or Cre controls (Fig. 3C); further subdividing cortical regions showed a

231 similar decrease (Supplemental Figs. 3A, C). Examination of PNNs at high magnification

232 showed that in the absence of AnkR, PNNs were less compact compared to control mice. We

233 classified the PNNs as being dense (0), having a few small holes (1), or having large numerous

234 holes (2) (Supplemental Fig. 3D). AnkR-deficient neurons were significantly less likely to be

235 compact and more likely to have holes in their nets (Figs. 3D, E). In 12-month-old mice we

236 found a significant reduction in the number of $\mathrm{WFA}^{+} / \mathrm{Pv}^{+}$cells per unit area in the hippocampus

237 and cortex of $A n k 1^{F / F} ; D / \times 5 / 6$-Cre mice compared to floxed or Cre controls (Figs. 3F, G). In

238 addition, and like in the one-month-old $A n k 1^{F / F} ; D / \times 5 / 6-C r e$ mice, we measured a 50\% decrease

239 in the WFA fluorescence intensity in both hippocampus and cortex (Fig. 3H). This significant

240 reduction in WFA was seen in all cortical regions (Supplemental Fig. 3B). The normally compact

241 PNN structure, as observed in 12-month-old control mice, was also significantly disrupted in

$242 A n k 1^{F / F} ; D l \times 5 / 6$-Cre mice with even more prominent holes in the PNNs compared to either

243 control or one-month-old $A n k 1^{F / F} ; D / x 5 / 6$-Cre mice (Figs. 3I, J, and Supplemental Movies 1, 2).

244 Furthermore, the strong reduction in NrCAM immunoreactivity seen in Ank $1^{\mathrm{F} / F}$;Nes-Cre mouse

245 brain (Fig. $2 \mathrm{~J}$ ) was matched by a strong reduction in WFA ${ }^{+}$cells in the same region

246 (Supplemental Figs. 2G, H). Together, these results suggest that loss of AnkR does not disrupt

247 the ability of PNNs to form, but rather AnkR helps maintain PNNs and their normal compact

248 structure through binding to PNN-interacting CAMs like NrCAM and PlexinA4. 
To determine if loss of AnkR from GABAergic interneurons alters nervous system

252 function, we analyzed the behavior of $A n k 1^{F / F} ; D / x 5 / 6$-Cre mice compared to control mice

$253\left(A n k 1^{F / F}\right.$ and $\left.A n k 1^{+/+} ; D / \times 5 / 6-C r e\right)$. We first performed a 30-minute open field assessment to rule

254 out locomotor deficits (Fig. 4A and Supplemental Fig. 4A-C) since a hypomorph of AnkR was

255 previously reported to have a loss of Purkinje neurons by 6 months of age (Peters et al., 1991).

256 We found that all genotypes analyzed had normal locomotion, but both Ank1+/+;D/x5/6-Cre and

$257 A n k 1^{F / F} ; D / x 5 / 6$-Cre mice showed increased velocity and distance traveled compared to Ank1 $1^{F / F}$

258 mice. These results are consistent with previous reports that the D/x5/6-Cre transgene results in

259 a hyperactive phenotype characterized by increased velocity and movement(de Lombares et

260 al., 2019). Nevertheless, during the open field assessment, Ank1 ${ }^{F / F} ; D / x 5 / 6-C r e$ mice spent

261 significantly more time in the center of the arena and less time in the perimeter compared to

262 both $A n k 1^{F / F}$ and $A n k 1^{+/+} ; D / x 5 / 6$-Cre mice (Fig. 4B, C), suggesting that loss of AnkR may be

263 anxiolytic.

To further distinguish between increased activity and decreased anxiety-like behaviors,

we used the elevated plus maze (EPM) (Fig. 4D). In contrast to the open field assessment, during a 10-minute trial in the EPM we observed no difference among the three genotypes in the velocity or total distance traveled in all arms (Supplemental Fig. 4D-E). However, we measured a significant increase in the distance traveled in the open arms, the time spent in the open arms, and the number of open arm entries performed by $A n k 1^{F / F} ; D / x 5 / 6$-Cre mice compared to control mice (Fig. 4E-G). Together, these data suggest that loss of AnkR from

271 forebrain GABAergic neurons reduces anxiety-like behaviors.

To determine how loss of AnkR impacts the intrinsic excitability and firing properties of

276 fast-spiking interneurons, we performed whole-cell current clamp recordings on layer $5 \mathrm{PNN}^{+}$

277 interneurons in somatosensory cortical slices from $A n k 1^{\mathrm{F} / F}, A n k 1^{+/+} ; D / \times 5 / 6-C r e$, and

$278 A n k 1^{F / F} ; D / x 5 / 6$-Cre mice. Fast-spiking interneurons were identified in live brain slices by labeling

279 PNNs with fluorescent WFA (Supplemental Fig. 5A-C). Indeed, 64 out of 66 WFA $^{+}$cells recorded 
were fast-spiking interneurons and the 2 non-fast spiking cells were not included in the analysis.

281 We found that the resting membrane potential, input resistance, membrane capacitance, and

282 rheobase current were not significantly altered in Ank1 ${ }^{F / F} ; D / x 5 / 6-C r e$ neurons compared to

283 controls (Supplemental Table 1). We determined the action potential latency, threshold,

284 amplitude, half-width, afterhyperpolarization (AHP) amplitude, and AHP time from the single

285 action potential elicited by the rheobase current (Figure 5A). Loss of AnkR decreased the action

286 potential latency and threshold (Fig. 5B, C, and Supplemental Table 1) without changing the

287 amplitude of the action potential (Fig. 5D, and Table 1). Interestingly, loss of AnkR also altered

288 the shape of the action potential, resulting in a $47 \%$ broader action potential with a shallower

289 and delayed AHP (Fig. 5E-H, and Supplemental Table 1).

We also recorded trains of action potentials evoked by different levels of current

291 injection (Fig. 5I, J). At 2 times the action potential threshold current, fast-spiking interneurons

292 from $A n k 1^{F / F} ; D / x 5 / 6$-Cre mice display a decreased firing frequency during the first $100 \mathrm{~ms}$ of

293 current injection (Fig. 5K), but normal spike frequency adaptation (Fig. 5L). However, the spike

294 amplitude adaptation was enhanced, resulting in a strong reduction in the amplitudes of action

295 potentials towards the end of spike trains (Fig. 5I, M). In fact, Ank1 ${ }^{F / F} ; D / \times 5 / 6-C r e$ cells often

296 entered depolarization block at much lower current levels than control cells (Fig. 5I, N). Thus,

297 the reduction in firing frequency for $A n k 1^{F / F} ; D / x 5 / 6-C r e$ cells at high levels of current injection is

298 actually an underestimation, because many $A n k 1^{F / F} ; D / \times 5 / 6-C r e$ cells prematurely reached

299 depolarization block and were not represented by the current-firing frequency curve (Fig. 5J).

In addition to examining intrinsic excitability of fast-spiking interneurons we also

301 performed whole-cell voltage clamp recordings to record miniature postsynaptic currents. We

302 observed no significant differences between the controls and Ank1F/F;D/x5/6-Cre mice for the

303 frequency and amplitude of miniature excitatory postsynaptic currents (mEPSC) or miniature

304 inhibitory postsynaptic currents (mIPSC), as well as the ratio of excitatory to inhibitory inputs

305 (E/I ratio) (Supplemental Fig. 5D-I). Taken together, these results show that loss of AnkR alters

306 the intrinsic properties of WFA fast-spiking inhibitory interneurons. Furthermore, they are

307 consistent with what has been reported in another model where PNNs of fast-spiking

308 interneurons are disrupted due to loss of Bcan (Favuzzi et al., 2017); however loss of Bcan also 
induced changes in mPSCs. Intriguingly, the results are very similar to those seen in mice with loss of $\mathrm{Kv3} \mathrm{K}^{+}$channel expression in fast-spiking interneurons (Lau et al., 2000). Hence, we hypothesize that loss of AnkR may impact Kv3 $\mathrm{K}^{+}$channel function.

\section{AnkR recruits and maintains $\mathrm{Kv3.1b} \mathrm{K}^{+}$channels at the neuronal membrane}

Among the Kv channels, Kv3.1b is highly expressed in WFA ${ }^{+}$cortical interneurons (Hartig et al., 1999); Kv3.1b is also found at some CNS nodes of Ranvier, but not AIS (Devaux et al., 2003). Similarly, AnkR is enriched in WFA+ cortical interneurons (Fig. 2I), and can be found at some nodes of Ranvier (Ho et al., 2014), but not AIS (Liu et al., 2020a). Based on these similarities, we considered $\mathrm{Kv} 3.1 \mathrm{~b}$ to be a good candidate to interact with AnkR in somatic membranes of WFA ${ }^{+}$cortical interneurons. Immunostaining of control 1- and 12-month-old somatosensory cortex showed that $\mathrm{AnkR}^{+}$neurons were also Kv3.1b+ (Fig. 6A, and Supplementary Fig. 6A), and that AnkR and Kv3.1b colocalize at the neuronal membrane (Fig. 6B). This same colocalization was also seen in human cortex (Fig. 6C). Remarkably, AnkRdeficient $A n k 1^{F / F} ; D / \times 5 / 6-C r e$ mice have a profound reduction in Kv3.1 $\mathrm{b}^{+}$neurons at both 1 - and 12-months of age (Figs. 6A, B, and Supplementary Fig. 6A) and nearly complete loss of Kv3.1b immunofluorescence (Fig. 6D). Compared to controls, Ank1 ${ }^{\mathrm{F} / F} ; \mathrm{D} / \times 5 / 6$-Cre mice have a $~ 50 \%$ reduction in Kv3.1b protein (Figs. 6E, F), which persists in 12-month-old mice (Supplementary Fig. $6 \mathrm{~B}, \mathrm{C})$. These results show that AnkR is required to maintain clustering of Kv3.1b in the somatic membrane of GABAergic interneurons.

To determine if AnkR and Kv3.1b interact, we co-transfected HEK cells with AnkR-GFP and Flag-tagged Kv3.1b. AnkR-GFP efficiently co-precipitates full-length Flag-Kv3.1b (Fig. 6G). We then constructed serial C-terminal truncations of Flag-Kv3.1b. We found that AnkR-GFP pulled down amino acids (aa) 1-546 of Kv3.1b (Fig. 6G). However, additional shortening of the C-terminus blocked the interaction with AnkR. Thus, AnkR binds to the region of Kv3.1b including aa 510-546 (Fig. 6G). To further define the motif in Kv3.1b that interacts with AnkR, we generated additional C-terminal deletions of just 6 aa each, spanning aa 510-546 of Kv3.1b. We found that aa 516-522 of Kv3.1b (EDCPHI) are required for AnkR binding (Fig. 6H). A nearly identical motif is also present in Kv3.3, but not Kv3.2 (Fig. 6I). Kv3.3 is also highly expressed in 
$\mathrm{Pv}^{+}$neurons (Chang et al., 2007) and immunostaining of control one-month-old somatosensory cortex showed that a subset of AnkR+ neurons also express Kv3.3 (Supplementary Fig. 6D). Using brain homogenates, we found that Kv3.1b, but not Kv2.1, co-immunoprecipitates AnkR (Fig. 6J). However, we were unable to detect Kv3.1b after immunoprecipitation of AnkR; this may suggest that only a small fraction of the total AnkR interacts with Kv3.1b. Together, these results show that AnkR binds directly to Kv3.1b.

Since Kv3.1b interacts with AnkR and is required for its membrane localization (Figs. 6A, b), we next determined if AnkR is sufficient to recruit Kv3.1b to neuronal membrane domains. Although some CNS nodes of Ranvier have clustered Kv3.1b, most PNS nodes of Ranvier normally have high levels of Kv7.2/3 K+ channels rather than Kv3.1b (Figs. 6K, L) (Pan et al., 2006). Kv7.2 $\mathrm{K}^{+}$channel clustering requires binding to AnkG since Kv7.2 is absent from nodes in the ventral roots of AnkG-deficient $\left(A n k 3^{F / F} ; C h A T-C r e\right)$ mice (Figs 6K, L). AnkR clusters nodal $\mathrm{Na}^{+}$channels(Ho et al., 2014) and NF186 in the ventral roots of Ank3 ${ }^{\mathrm{F} / \mathrm{F}}$;ChAT-Cre mice (Fig. 6K). Although very few nodes in ventral root normally have Kv3.1b (Figs. 6L), the replacement of AnkG by AnkR in Ank3 ${ }^{F / F}$;ChAT-Cre mice is sufficient to recruit and cluster Kv3.1b to nearly all nodes (Figs. 6K, L); and nodes in control spinal cord that have high levels of AnkR also have clustered Kv3.1b (Supplemental Fig. 6E). Similarly, AnkR recruits Kv3.3 K+ channels to nodes in AnkG-deficient ventral root axons (Supplemental Fig. 6E). Together, these results show that although AnkG and AnkR can both cluster $\mathrm{Na}^{+}$channels at nodes of Ranvier, AnkG preferentially clusters Kv7.2/3 $\mathrm{K}^{+}$channels and links them to the cytoskeleton through $\alpha 2 / \beta 4$ spectrin (Huang et al., 2017b), while AnkR is both necessary and sufficient to recruit Kv3.1b/3 $\mathrm{K}^{+}$channels to neuronal membranes and nodes of Ranvier, and links them to the cytoskeleton through $\alpha 2 / \beta 1$ spectrin (Ho et al., 2014; Huang et al., 2017a) (Supplemental Fig. 6G). Thus, the type of $\mathrm{K}^{+}$ channel found at nodes of Ranvier is dictated by ankyrins.

\section{DISCUSSION}

Ankyrins are well-known to function in neurons as scaffolds that link ion channels and membrane proteins to the spectrin cytoskeleton (Bennett and Lorenzo, 2013). We previously showed that in the absence of AnkG, AnkR can function at nodes of Ranvier as a secondary $\mathrm{Na}^{+}$ 
channel clustering mechanism (Ho et al., 2014). The rescue depends on AnkR's recruitment to nodes from a pre-existing, unclustered pool. These findings motivated us to determine AnkR's normal functions in the nervous system since it is unlikely that AnkR functions only as a backup for nodal $\mathrm{Na}^{+}$channel clustering, since pathogenic ANK1 variants are associated with nervous system dysfunction, and since altered methylation of $A N K 1$ is associated with AD. Our

372 experiments confirm that in general, AnkR acts as a scaffolding protein like AnkB and AnkG.

373 However, unlike AnkB and AnkG which are broadly expressed in all neurons, AnkR is highly and 374 specifically enriched in subsets of neurons, including fast-spiking GABAergic interneurons,

375 where it assembles and stabilizes unique protein complexes necessary for the proper function 376 of these cells (Fig. 7).

\section{AnkR maintains PNNs}

GABAergic interneurons are surrounded by PNNs, and our proteomics experiments revealed that AnkR indirectly interacts with PNN components (Fig. 7). PNNs are proposed to have many functions including regulation of synaptic plasticity, excitation and inhibition, ion buffering, and even protection against neurodegeneration and neurotoxicity (Cabungcal et al., 2013; Fawcett et al., 2019; Suttkus et al., 2016b). The connection between AnkR and PNNs is remarkably similar to the connection between AnkG and perinodal and AIS ECMs. These latter ECMs interact with AnkG through the CAM NF186, and loss of either AnkG or NF186 blocks their assembly (Amor et al., 2017; Hedstrom et al., 2007; Susuki et al., 2013). In contrast, the membrane receptors and mechanisms of PNN assembly and maintenance are unknown. Our proteomics experiments revealed candidates and suggest that NrCAM and PlexinA4, together with Nrp1, may participate in assembly or maintenance of PNNs. These CAMs co-

390 immunoprecipitate with AnkR. NrCAM and Nrp1 colocalize with a subset of AnkR ${ }^{+}$neurons.

391 Furthermore, loss of AnkR dramatically reduces the number of somatodendritic $\mathrm{NrCAM}^{+} / \mathrm{WFA}^{+}$ 392 neurons, suggesting that as for PNNs, AnkR is required to maintain somatodendritic NrCAM in 393 WFA $^{+}$neurons. Future studies of PNNs in NrCAM and PlexinA4-deficient mice may help to 394 determine the role of these CAMs in PNN assembly and maintenance. In addition, other 395 interesting candidates identified in our proteomics experiments may also function as receptors. 
396 For example, we identified the adhesion G-protein coupled receptor Gpr158 and the CAM

397 Limbic System Associated Membrane Protein (Lsamp). It will be interesting and important to

398 determine if these membrane proteins also function with AnkR to assemble, modulate, or

399 maintain PNNs, and we speculate that multiple receptors link AnkR to PNNs.

400 We observed the disruption of the compact PNN structure and a $50 \%$ reduction in WFA

401 fluorescence intensity in the absence of AnkR in juvenile and adult mice. This is notable since

402 mice lacking four PNN components (TnC, TnR, and the CSPGs Bcan and neurocan) have a

403 significant reduction in PNN structure, area, and WFA fluorescence during development, but

404 PNNs normalize by postnatal day 35 (Gottschling et al., 2019). Thus, loss of AnkR has more

405 profound effects on maintenance of PNNs than even removing components of the PNNs

406 themselves. This suggests that although AnkR is not necessary for the assembly of PNNs, the

407 receptors responsible for PNN maintenance converge on AnkR (Fig. 7). Nevertheless, since

408 PNNs still assemble in the absence of AnkR, other AnkR-independent PNN assembly

409 mechanisms must also exist.

410

411 AnkR, PNNs, and psychiatric disease

412 Mice lacking AnkR in GABAergic interneurons showed reduced anxiety in both the open

413 field and elevated plus maze tests. Increased anxiety has been correlated with increased PNN

414 density (Murthy et al., 2019). Conversely, the selective serotonin reuptake inhibitor (SSRI)

415 fluoxetine reduces anxiety as well as PNN density (Ohira et al., 2013). The results of these

416 studies are consistent with our observation that $A n k 1^{F / F} ; D / \times 5 / 6-C r e$ mice have both reduced

417 anxiety and a significant reduction in PNN density (Fig. 7). Some studies have reported large

418 reductions in PNNs throughout the brains of patients with schizophrenia (Berretta, 2012;

419 Mauney et al., 2013). Multiple GWAS studies implicate ANK1 as a schizophrenia-associated

420 gene (Aberg et al., 2013; Fromer et al., 2014; Schizophrenia Working Group of the Psychiatric

421 Genomics, 2014), and several of the top candidates for AnkR-interacting proteins identified in

422 our mass spectrometry analysis (e.g. Myh11, Kif1a, Itsn1, and Slc25a12) are also schizophrenia-

423 associated genes (Fromer et al., 2014; Schizophrenia Working Group of the Psychiatric

424 Genomics, 2014); Kv3.1b is also reduced in patients with schizophrenia (Yanagi et al., 2014). 
425 Thus, dysregulation of $A N K 1$, leading to reduced AnkR, Kv3.1b, and PNN density, may be a

426 common pathomechanism in psychiatric disease. Intriguingly, the expression of Kv3.1b in

427 schizophrenic patients is corrected by antipsychotic drugs (Yanagi et al., 2014). It will be

428 interesting to determine if antipsychotic drugs similarly affect AnkR protein levels or PNNs.

\section{AnkR recruits Kv3.1b to the neuronal membrane}

Loss of AnkR from GABAergic interneurons significantly altered their intrinsic and firing properties, suggesting disrupted $\mathrm{K}^{+}$channel function. However, the changes in excitability may also reflect loss of both $\mathrm{Kv} 3.1 \mathrm{~b} \mathrm{~K} \mathrm{~K}^{+}$channels and reduced PNNs, since Bcan-deficient mice have similar changes in the excitability of their GABAergic interneurons (Favuzzi et al., 2017). We found that AnkR interacts directly with Kv3.1b and is required to maintain Kv3.1b in GABAergic neurons. We localized Kv3.1b's AnkR-binding motif to 6 residues in its C-terminus: EDCPHI. This motif is different than the previously characterized pan ankyrin-binding motifs present in all $\mathrm{Na}^{+}$channels (Garrido et al., 2003) and L1CAMs (Garver et al., 1997; Tuvia et al., 1997). In contrast, there is specificity among the ankyrin-binding capacities of different $\mathrm{K}^{+}$channels: AnkR interacts with Kv3.1b and is both necessary and sufficient to induce Kv3.1b clustering in the soma of GABAergic interneurons and a subset of CNS nodes of Ranvier, while AnkG binds $\mathrm{Kv7.2/3}$ and is necessary and sufficient for its clustering at AIS and nodes of Ranvier. Although the Kv7.2/3 motif is highly homologous to the $\mathrm{Na}^{+}$channel ankyrin-binding motif, AnkR does not cluster Kv7.2/3 (Wang et al., 2018). When Kv3.1b is present at nodes, it is associated with AnkR. A nearly identical motif is also present in Kv3.3. Like Kv3.1b, Kv3.3 is enriched in Pv

446 interneurons in the forebrain, hippocampus, deep cerebellar nuclei and Purkinje neurons in the cerebellum (Chang et al., 2007); these same cells also express high levels of AnkR (Kordeli and

448 Bennett, 1991). Although one previous study suggested Kv3.3 is not found at nodes (Chang et al., 2007), our results show that CNS nodes with AnkR have both Kv3.1b and Kv3.3, most likely

450 as heterotetramers. Thus, $\mathrm{K}^{+}$channel diversity among nodes of Ranvier is dictated by the 451 specific ankyrin scaffolds present at nodes. 
A number of epigenome-wide association studies in Alzheimer's disease patients consistently report neuropathology-associated DNA hypermethylation of ANK1 (De Jager et al.,

456 2014; Higham et al., 2019; Lunnon et al., 2014; Smith et al., 2019a; Smith et al., 2019b).

457 However, the consequence of this hypermethylation for AnkR protein expression is unknown.

458 Experiments in APP/PS1 mice also report significant reductions in Kv3.1b (Boda et al., 2012).

459 Since Kv3.1b levels in GABAergic neurons depend on AnkR, reduced expression of AnkR in the

460 AD brain could result in altered neuronal excitability or circuit function due to the decreased

461 levels of Kv3.1b. Similarly, PNN density has been reported to be reduced in both human AD

462 brains and brains from the 5xFAD mouse model of AD (Crapser et al., 2020). Although these

463 studies suggested that activation of microglia disrupted PNNs, our experiments show that

464 another mechanism could be reduced expression of AnkR. PNNs are thought to protect against

465 neurodegeneration since the loss of PNNs renders neurons more susceptible to accumulation

466 of neurofibrillary tangles comprising phosphorylated tau, and lipofuscin (Suttkus et al., 2016a;

467 Suttkus et al., 2016b), and neurons without PNNs are more susceptible to A $\beta 1-42$ toxicity

468 (Miyata et al., 2007). Thus, reduced AnkR expression may decrease PNN density, thereby

469 rendering neurons more susceptible to injury in AD.

$470 \quad$ Since mutations in AnkR cause severe hemolytic anemia, its role in the nervous system

471 has mostly been ignored. However, our results demonstrate that AnkR is much more than just

472 red blood cell ankyrin. Our studies reveal AnkR's critical role in fast-spiking GABAergic

473 interneurons, its interacting proteins, and show that AnkR is necessary for normal interneuron

474 function.

475

\section{ACKNOWLEDGEMENTS}

477 The work reported here was supported by the following research grants from the National 478 institutes of Health: R01 NS044916 (MNR), R01 GM103481 (ALB), R01 MH117089 (MX), R01 479 NS100893 (MX), F31 NS100300 (SRS), F30 MH118804 (CML), RF1 NS118584 (MDC). This work 480 was also supported by the Dr. Miriam and Sheldon G. Adelson Medical Research Foundation 481 (ALB and MNR), the HMH Clinician Scientist Award (MDC), and a Houston Methodist 482 Hospital/Baylor College of Medicine collaborative pilot grant in Alzheimer's disease and related 
483 dementias. CML is part of the Baylor College of Medicine Medical Scientist Training Program

484 and McNair MD/PhD Student Scholars supported by the McNair Medical Institute at the Robert

485 and Janice McNair Foundation. MX is a Caroline DeLuca Scholar.

\section{AUTHOR CONTRIBUTIONS}

488 Conceptualization, Methodology, Validation, Data Curation, Investigation, and Writing -

489 Original Draft and Editing, S.R.S; Methodology, Data Curation, Investigation, and Writing -

490 Original Draft and Editing, C.M.L; Investigation L.H.T., S.N., and Y.O.; Methodology, Data

491 Curation, Writing - Original Draft and Editing, A.S.A; Data Curation, Resources, and Writing -

492 Review and Editing, J.O-P.; Resources, Supervision, Funding Acquisition, and Writing - Review

493 and Editing, A.L.B., Methodology, Investigation, Funding Acquisition, and Writing - Review and

494 Editing, M.D.C; Methodology, Supervision, Funding Acquisition, and Writing - Review and

495 Editing, M.X.; Conceptualization, Methodology, Data Curation, Funding Acquisition, Writing -

496 Original Draft and Editing, and Project Administration, M.N.R.

499 The authors declare no competing financial interests 
MATERIALS AND METHODS

Animals. AnkR conditional knockout mice were generated using cell-type-specific Cre-mediated

503 deletion of the Ank1 gene. The targeting construct was designed by introducing loxP sites

504 flanking exons 26 and 27 of Ank1, upstream of the spectrin binding domain. The Cre-mediated

505 removal of these exons will cause a frame-shift mutation resulting in a premature stop codon in

506 exon 28. Forward primer: 5'-GGG AAA CTC CAC AGA GCC TGA CGG GTC AGT-3', Reverse primer:

507 5'- GGC GTC CCT ATG TTC CAT CCT ATA GAT GAC T-3'. Generation of the target construct, ES

508 cell electroporation, colony selection, blastocyst injection, and generation of chimeric mice

509 were a service of the University of Rochester Medical Center Transgenic Core Facility. The

510 strategy is similar to that successfully used to create the Ank2 and Ank3 floxed mice where loxP

511 sites flank exons 23/24 and 22/23, respectively(Chang et al., 2014; Ho et al., 2014). Ank1 ${ }^{F / F}$ mice

512 were generated and backcrossed to C57BL/6 (IMSR Cat\# JAX:000664, RRID:IMSR_JAX:000664)

513 for at least four generations before being crossed to Nestin-Cre transgenic mice (IMSR Cat\#

514 JAX:003771, RRID:IMSR_JAX:003771), DIx5/6-Cre transgenic mice (IMSR Cat\# JAX:008199,

515 RRID:IMSR_JAX:008199). Ank1 $1^{\text {pale/pale }}$ mice were obtained from Jackson Laboratory (IMSR Cat\#

516 JAX:009157, RRID:IMSR_JAX:009157). Since germline recombination has been found to occur in

517 these Cre lines(Luo et al., 2020), immunostaining using anti-AnkR antibodies was used as a

518 secondary confirmation of genotype. Ank3 ${ }^{F / F}$ mice (IMSR Cat\# JAX:029797,

519 RRID:IMSR_JAX:029797) were crossed with ChAT-Cre transgenic mice (IMSR Cat\# JAX:006410,

520 RRID:IMSR_JAX:006410). Both male and female mice were used in our studies. All experiments

521 were conducted in compliance with the National Institutes of Health Guide for the Care and Use

522 of Laboratory Animals and were approved by the Animal Care and Use Committee at Baylor

523 College of Medicine.

525 Blood transfusion and bone marrow transplant in Ank $1^{\text {pale/pale }}$ animals. The pale mutation in

526 Ank1 results in severe anemia characterized by pale skin tone at birth and death within one to

527 two weeks of age(Ho et al., 2014). We performed a blood transfusion at P1 and subsequent

528 bone marrow transplant at P30 which enabled $A n k 1^{\text {pale/pale }}$ animals to survive into adulthood.

529 Animals received a $5 \mathrm{~mL} / \mathrm{kg}$ body weight external jugular vein blood transfusion at $\mathrm{P} 1$, and 
$5305 \mathrm{~mL} / \mathrm{kg}$ bone marrow transplant into the tail vein at P30. Blood was collected from the male

531 breeding mouse and washed with two-times volume of saline prior centrifugated at 700Xg for

$53220 \mathrm{~min}$ at $4^{\circ} \mathrm{C}$ to remove excess plasma and debris. Bone marrow was isolated from the tibia

533 and femur of close genealogical donor mice. In brief, bones were extracted and placed in $3 \mathrm{~mL}$

$5342 \%$ fetal bovine serum (FBS) HBSS (without $\mathrm{Ca}^{2+}$ and $\mathrm{Mg}^{2+}$ ). Marrow was exposed by cutting

535 with sterile scissors and a 25 gauge needle and $3 \mathrm{~mL}$ syringe were used to expunge the marrow

536 into a sterile $6 \mathrm{~cm}$ dish with $2 \%$ FBS HBSS on ice. Cells were then filtered through $1 \mathrm{~cm}^{2} 100 \mu \mathrm{m}$

537 nylon mesh into a $5 \mathrm{~mL}$ FACS tube. Cells were counted and diluted to an injection concentration

538 of 3 million cells/100 $\mu \mathrm{L}$ volume. Throughout life, all animals were closely monitored for

539 changes in weight and behavior.

540

541 Behavioral Tests. Mice aged to 9-14 weeks were handled for 3 days prior to the start of testing.

542 Animals began with the open field assessment followed by the elevated plus maze to assess

543 locomotor activity and anxiety. The open field assessment was conducted in white acrylic open-

544 top boxes $(46 \times 46 \times 38 \mathrm{~cm})$ in a room lit by indirect white light for 30 minutes. Following this,

545 animals were given 2-3 hours rest in their home cages. The elevated plus maze assessment was

546 then conducted on an elevated platform for 10 minutes. Activity for these tasks was recorded

547 and analyzed using the ANY-maze Video Tracking System version 4.99v (Stoelting Co, Wood

548 Dale, IL).

549

550 Antibodies. The primary antibodies used here include: mouse monoclonal antibodies against

551 AnkR (UC Davis/NIH NeuroMab Facility Cat\# 75-380, RRID:AB_2491109), $\beta 1$ spectrin (UC

552 Davis/NIH NeuroMab Facility Cat\# 73-374, RRID:AB_2315814), AnkG (UC Davis/NIH NeuroMab

553 Facility Cat\# 73-146, RRID:AB_10697718), parvalbumin (UC Davis/NIH NeuroMab Facility Cat\#

554 73-455, RRID:AB_2629420), actin (Millipore Cat\# MAB1501, RRID:AB_2223041), tenascinR (R

555 and D Systems Cat\# MAB1624, RRID:AB_2207001), aggrecan (Millipore Cat\# AB1031,

556 RRID:AB_90460), brevican (UC Davis/NIH NeuroMab Facility Cat\# 75-294, RRID:AB_2315824),

557 NrCAM (R and D Systems Cat\# MAB2034, RRID:AB_2267411), Kv3.1b (UC Davis/NIH NeuroMab

558 Facility Cat\# N16B/8, RRID:AB_2750730 and Thermo Fisher Cat\# MA5-27684, 
559

560

561

562

563

564

565

566

567

568

569

570

571

572

573

574

575

576

577

578

579

580

581

582

583

584

585

586

RRID:AB_2735238), Kv3.3 (Antibodies-Online Cat\# ABIN572016, RRID:AB_10782137), Kv7.2

(James Trimmer, University of California at Davis Cat\# N26A/23, RRID:AB_2750761), Flag-tag or DDDDK-tag (MBL International Cat\# M185-3L, RRID:AB_11123930); rabbit polyclonal antibodies against AnkR(Ho et al., 2014) (RRID:AB_2833096), Ank1 (Thermo Fisher Scientific Cat\# PA563372, RRID:AB_2638015), neurofilament M (Millipore Cat\# AB1987, RRID:AB_91201), parvalbumin (Novus Cat\# NB120-11427, RRID:AB_791498), versican (Millipore Cat\# AB1032, RRID:AB_11213831), PlexinA4 (Abcam Cat\# ab39350, RRID:AB_944890), and neuropilin-1 (GeneTex Cat\# GTX16786, RRID:AB_422398), Kv3.1b (Alomone Labs Cat\# APC-014, RRID:AB_2040166), Kv3.3 (Alomone Labs Cat\# APC-102, RRID:AB_2040170), GFP (Thermo Fisher Scientific, Cat\# A-11122, RRID: AB_221569); and chicken polyclonal antibody against Neurofascin (R and D Systems Cat\# AF3235, RRID:AB_10890736). Wisteria Floribunda lectins used were: Fluorescein labeled (Vector Laboratories Cat\# FL-1351, RRID:AB_2336875 and Bioworld Cat\# 21761065-1, RRID:AB_2833087), and Texas-Red (EY Laboratories Cat\# F-3101-1, RRID:AB_2315605). Secondary antibodies were purchased from Jackson ImmunoResearch Laboratories or Life Technologies (IgG specific mouse antibodies). We encourage researchers to determine the optimal antibody dilutions for themselves as varying tissue treatment can affect staining conditions.

Immunofluorescence. Animals were transcardially saline perfused to reduce red blood cells, then brains, spinal cords and roots were dissected and fixed in 4\% paraformaldehyde (1 hour for brains and $30 \mathrm{~min}$ for spinal cords and roots) on ice and subsequently immersed in $20 \%$ sucrose overnight at $4^{\circ} \mathrm{C}$. Tissue was embedded in Tissue-Tek OCT (Sakura Finetek 4583) mounting medium, and frozen on dry ice. Brains were sectioned at $25 \mu \mathrm{m}$ thickness, ventral roots at $14 \mu \mathrm{m}$ thickness, and spinal cords were sectioned at $18 \mu \mathrm{m}$ thickness using a cryostat (Thermo Fisher Scientific Cryostar NX70). Sections were placed on 1\% bovine gelatin precoated coverslips (Thermo Fisher Scientific). Sections were blocked with 10\% normal goat serum in $0.1 \mathrm{M}$ phosphate buffer (PB) with $0.3 \%$ Triton X-100 for 1 hour at room temperature. Primary antibodies diluted in the blocking buffer and incubated at room temperature overnight, then 
sections were washed with blocking buffer. Secondary antibodies and lectins were incubated at room temperature for 2 hours and washed with 0.1M PB.

For immunostaining of human tissues, sections were deparaffinized and rehydrated through a series of alcohols and water. Heat-based antigen retrieval was performed using $1 \times$ antigen retrieval solution at pH 9 (Agilent Technologies; Santa Clara, CA) for 1 hour (30 min at 95C, followed by 30 min on ice). Washes with fresh phosphate-buffered saline with Tween 20 (PBS-T) were then performed and PBS with 0.3\% Triton X-100 (Sigma, T8787) was applied for 10 minutes. After additional washes with PBS-T, slides were blocked with $2.5 \%$ horse serum (Vector Laboratories, Burlingame, CA) with 1\% Tween 20 (ThermoFisher, BP337) and 0.1\% BSA in PBS (Thermo Scientific, 37525). Primary antibody along with the above blocking solution was applied for 1-2 hours at room temperature. Secondary antibodies were applied for 1 hour at room temperature, including Alexa Fluor 555 Anti-Rabbit IgG (1:200; A21429), Alexa Fluor 555 Anti-Mouse IgG (1:200; A32727), Alexa Fluor 488 anti-Mouse IgG (1:200; A11001), and Alexa Fluor 488 anti-Rabbit IgG (1:200; A11034) (Alexa Fluor products of ThermoFisher), as appropriate. For double-labeling studies, dilutions of both primary and secondary antibodies were combined in $2.5 \%$ horse serum and applied. Slides were mounted using Vectashield Antifade mounting medium with 4',6-diamidino-2-phenylindole (DAPI; Vector Laboratories). These studies were carried out with IRB approval from Houston Methodist Hospital (Pro00010377).

Image Analysis. Immunofluorescence labeling was visualized and images were collected on an Axiolmager (Carl Zeiss) fitted with an apotome for optical sectioning, and a digital camera (AxioCam; Carl Zeiss). AxioVision (Carl Zeiss) acquisition software was used for collection of images. Images were also collected using a Nikon Eclipse Ni-E microscope fitted with a motorized $X-Y$ stage for acquisition of fields. Stitching of images was performed using NISElements (Nikon). In some instances, linear contrast and brightness adjustments were performed using Adobe Photoshop, or Z-stacks, 3D reconstruction, and cell counts were performed using NIH FIJI/ImageJ. The WFA or AnkR intensity were quantified as previously described(Gottschling et al., 2019; McCloy et al., 2014). In brief, NIH FIJI/ImageJ was used to 
616 draw an outline around each cell and circularity, area, mean fluorescence, along with several

617 adjacent background readings were measured. The corrected total cell fluorescence $(C T C F)=$

618 integrated density - (area of selected cell $\times$ mean fluorescence of background readings), was

619 calculated. These measurements were then averaged within and across multiple brain regions.

620 No other processing of the images was performed. Nodes in ventral roots were counted

621 manually. Nodes were determined to have AnkG, AnkR, Kv3.1b, or Kv7.2 if there was

622 immunofluorescence at the nodes. If there was not immunofluorescence, the node was

623 determined to be absent of AnkG, AnkR, Kv3.1b, or Kv7.2. Human immunofluorescence

624 preparations were reviewed by a neuropathologist (MDC). Images were captured in cellSens

625 software 1.13 (Olympus America, Inc.; Center Valley, PA) on an Olympus BX-43 Microscope

626 using a DP71 camera, an enhanced green fluorescent protein (EGFP) FITC/Cy2 filter cube (set

627 number 49002, Olympus; Center Valley, PA), and a CY3/tetramethylrhodamine-isothiocyanate

628 (TRITC) filter cube (set number 49004, Olympus). To examine the intensity and specificity of

629 antibody labeling, slides were first examined separately under DAPI, TRITC, and FITC filters,

630 photographed, and then merged in cellSens. All figures were assembled using Adobe

631 Illustrator.

632

633 Immunoblotting. Saline perfused mouse brains were homogenized in homogenization buffer

634 (0.32M sucrose, $5 \mathrm{mM} \mathrm{Na}_{3} \mathrm{PO}_{4}, 1 \mathrm{mM} \mathrm{NaF}, 0.5 \mathrm{mM}$ PMSF, $1 \mathrm{mM} \mathrm{Na} \mathrm{VO}_{4}$ and protease

635 inhibitors) in a Dounce homogenizer on ice. Homogenates were then centrifuged at 700Xg for

$63610 \mathrm{~min}$ at $4^{\circ} \mathrm{C}$ to remove nuclei and debris, the supernatants then underwent another

637 centrifugation at $27200 \mathrm{Xg}$ for $90 \mathrm{~min}$ at $4^{\circ} \mathrm{C}$. Pellets were resuspended in homogenization

638 buffer and protein concentrations were measured. The samples were resolved by SDS-PAGE,

639 transferred to nitrocellulose membrane, and immunoblotted with antibodies. Quantification of

640 immunoblots was done using NIH FIJI/ImageJ.

641

642 Plasmids. AnkR-GFP and $\beta 1$ spectrin-Myc constructs were previously described(Ho et al., 2014).

643 The full-length Kv3.1b construct was a gift from Dr. James Trimmer (University of California at

644 Davis). To generate Flag-tagged full-length or truncated Kv3.1b constructs, parts of Kv3.1b were 
645 PCR amplified from full-length Kv3.1b and then inserted into p3XFLAG-CMV-7.1 vector. DNA constructs were verified by sequencing (Genewiz).

Immunoprecipitation. Saline perfused mouse brains were homogenized in 20mM HEPES pH 7.4, 2mM EDTA and protease inhibitors in a Dounce homogenizer. 1\% (v/v) TX-100 was added to homogenates and solubilized on a shaker for $30 \mathrm{~min}$ at $37^{\circ} \mathrm{C}$. Lysates were then centrifuged at $700 \mathrm{Xg}$ for $20 \mathrm{~min}$ at $4^{\circ} \mathrm{C}$ to remove nuclei and debris, the supernatants then underwent another centrifugation at $27200 \mathrm{Xg}$ for $60 \mathrm{~min}$ at $4^{\circ} \mathrm{C}$. Lysates were collected and protein concentrations were measured. The lysates used for immunoprecipitation were prepared by dilution to final protein concentration at $1 \mathrm{mg} / \mathrm{ml}$ with lysis buffer (1\% (v/v) Triton X-100, 20 mM Tris- $\mathrm{HCl}$ pH 8.0, $10 \mathrm{mM}$ EDTA, $150 \mathrm{mM} \mathrm{NaCl} 10 \mathrm{mM} \mathrm{NaN}_{3}$ and protease inhibitors). Antibodies were added and samples were rotated overnight at $4^{\circ} \mathrm{C}$. Protein A (polyclonal antibodies, Thermo Scientific, 20333) or Protein G (monoclonal antibodies, GE Healthcare, 170618-01) agarose beads were washed with $1 \mathrm{ml}$ of lysis buffer three times and then rotated with the lysates for 1 hour at $4{ }^{\circ} \mathrm{C}$. The beads were then collected and washed with $1 \mathrm{ml}$ of icecold lysis buffer seven times and subjected to immunoblotting. were co-transfected with AnkR-GFP in HEK293T cells using PEI Max (Polysciences, 24765) according to the manufacturer's instructions. The media was replaced after 16-20 hours of 664 transfection. Cells were lysed at 48 hours of transfection in lysis buffer $(50 \mathrm{mM} \mathrm{Tris-HCl,} \mathrm{pH} 8.0$, $665150 \mathrm{mM} \mathrm{NaCl}, 0.1 \%$ TritonX-100, and $1 \mathrm{mM}$ EDTA with protease inhibitor), and the lysates were centrifuged at $14,000 \mathrm{rpm}$ for $10 \mathrm{~min}$ at $4^{\circ} \mathrm{C}$. Anti-GFP antibody was mixed with the supernatant and incubated overnight at $4^{\circ} \mathrm{C}$. Protein G Mag Sepharose (Cytiva), was first coated with 1 $\mathrm{mg} / \mathrm{ml}$ of BSA in lysis buffer for 1 hour at $4^{\circ} \mathrm{C}$ and washed 3 times with lysis buffer, and then

669 incubated with the mixture of cell lysate and antibody for 1 hour at $4^{\circ} \mathrm{C}$. After being washed 7

670 times with lysis buffer, the beads were eluted with $50 \mu \mathrm{l}$ of $1 \times$ Laemmli sample buffer at $95^{\circ} \mathrm{C}$

671 for $5 \mathrm{~min}$. The samples were analyzed by immunoblot using anti-Flag antibody. 
673 Mass Spectrometry. Brain homogenates were prepared as described above before lipid

674 extraction by acetone. Chilled pure acetone was added to homogenate $(4: 1)$ then vortexed to

675 precipitate and rotated overnight at $4^{\circ} \mathrm{C}$. Samples were then centrifuged at $27200 \mathrm{Xg}$ for $10 \mathrm{~min}$

676 at $4^{\circ} \mathrm{C}$ and washed twice with chilled acetone and water (4:1). The final pellet was air dried and

677 flash frozen on dry ice. Lysates for AnkR immunoprecipitation were prepared as described

678 above, except the final two washes of the beads were $20 \mathrm{mM}$ TrisHCl pH8, $2 \mathrm{mM} \mathrm{CaCl} 2$. The

679 beads were then collected and flash frozen on dry ice.

680 For digestion, pellets of lipid extracted brain homogenates were resuspended with

681 sonication in 8M guanidinium hydrochloride plus $200 \mathrm{mM}$ ammonium bicarbonate. Protein was

682 reduced by adding $10 \mathrm{mM} \mathrm{DTT}$ and incubating at $60^{\circ} \mathrm{C}$ for $30 \mathrm{~min}$. After that, samples were

683 treated with $20 \mathrm{mM}$ iodoacetamide at room temperature for $30 \mathrm{~min}$ and digested with $2 \%$

684 (W/W) Trypsin/LysC mix, mass spectrometry (MS) grade (Promega) for 4 hours at room

685

686

687

688

689

690

691

692

693

694

695

696

697

698

699

700

701

temperature. Samples were then diluted using $100 \mathrm{mM}$ ammonium bicarbonate so guanidinium hydrochloride concentration was $1 \mathrm{M}$ and incubated at $37^{\circ} \mathrm{C}$ overnight. After this, another $2 \%$ W/W aliquot of the digestion enzymes was added, and the digestion was allowed to continue for 4 hours at room temperature. Digested material was recovered using SepPacks C18 cartridges (Waters), eluted in $50 \%$ acetonitrile $0.1 \%$ formic acid, evaporated and resuspended in $0.1 \%$ formic acid for mass spectrometry analysis on a QExactive Plus (Thermo Scientific), connected to a NanoAcquity ${ }^{\mathrm{TM}}$ Ultra Performance UPLC system (Waters). $2 \mu$ g aliquots of the digests were injected in a $75 \mu \mathrm{m}$ x $15 \mathrm{~cm}$ PepMap RSLC C18 EasySpray column (Thermo Scientific) and peptides resolved in 90 min gradients with $0.1 \%$ formic acid in water as mobile phase $A$ and $0.1 \%$ formic acid in acetonitrile as mobile phase B. MS was operated in datadependent mode to automatically switch between MS and MS/MS. The top 10 precursor ions with a charge state of $2+$ or higher were fragmented by HCD. A dynamic exclusion window was applied which prevented the same $\mathrm{m} / \mathrm{z}$ from being selected for 30 s after its acquisition

For digestion of the immunoprecipitated samples, beads were resuspended in $36 \mu 10$ $\mathrm{mM}$ DTT in $100 \mathrm{mM} \mathrm{NH}_{4} \mathrm{HCO}_{3}$ and incubated for $30 \mathrm{~min}$ at room temperature. After this, iodoacetamide was added to a final concentration of $15 \mathrm{mM}$ and samples incubated for 30 additional minutes. $0.5 \mu \mathrm{g}$ of sequencing grade trypsin (Promega) was added to each sample 
and incubated at $37^{\circ} \mathrm{C}$ overnight. Supernatants of the beads were recovered, and beads consecutive digestions were recovered by solid phase extraction using C18 ZipTips (Millipore), eluted in $2 \times 7 \mu \mathrm{l}$ aliquots of $50 \% \mathrm{MeCN} 0.1 \%$ formic acid, dried and resuspended in $2.5 \mu \mathrm{l} 0.1 \%$ formic acid for mass spectrometry analysis. Peptides were separated using a $75 \mu \mathrm{m} \times 50 \mathrm{~cm}$ PepMap RSLC C18 EasySpray column (Thermo Scientific) using 3 hour gradients with 0.1\% formic acid in water as mobile phase $A$ and $0.1 \%$ formic acid in acetonitrile as mobile phase $B$,

709 for analysis in a Orbitrap Lumos Fusion (Thermo Scientific) in positive ion mode. MS was 710 operated in $3 \mathrm{~s}$ cycles in data-dependent mode to automatically switch between MS and

$711 \mathrm{MS} / \mathrm{MS}$, with a charge state of $2+$ or higher were fragmented by HCD. A dynamic exclusion

712 window was applied which prevented the same $\mathrm{m} / \mathrm{z}$ from being selected for 30 s after its

713 acquisition

714 In both cases, peak lists were generated using PAVA in-house software (Guan et al., 2011).

715 Generated peak lists were searched against the Mus musculus subset of the UniprotKB 716 database (UniProtKB.2013.6.17 for the full brain samples and UniProtKB.2017.11.01 for Ip 717 samples), using Protein Prospector (Clauser et al., 1999) with the following parameters: Enzyme 718 specificity was set as Trypsin, and up to 2 missed cleavages per peptide were allowed.

719 Carbamidomethylation of cysteine residues was allowed as fixed modification. $\mathrm{N}$-acetylation of 720 the $\mathrm{N}$-terminus of the protein, loss of protein $\mathrm{N}$-terminal methionine, pyroglutamate formation 721 from peptide $\mathrm{N}$-terminal glutamines, and oxidation of methionine were allowed as variable 722 modifications. Mass tolerance was $10 \mathrm{ppm}$ in MS and $30 \mathrm{ppm}$ in MS/MS. The false positive rate 723 was estimated by searching the data using a concatenated database which contains the original 724 UniProtKB database, as well as a version of each original entry where the sequence has been 725 randomized. A 1\% FDR was permitted at the protein and peptide level.

727 Brain slice electrophysiology. All electrophysiological experiments were performed and 728 analyzed blind to the genotypes. Mice were anesthetized by an intraperitoneal injection of a 729 ketamine and xylazine $\mathrm{mix}(80 \mathrm{mg} / \mathrm{kg}$ and $16 \mathrm{mg} / \mathrm{kg}$, respectively) and transcardially perfused 730 with cold $\left(0-4^{\circ} \mathrm{C}\right)$ slice cutting solution containing $80 \mathrm{mM} \mathrm{NaCl}, 2.5 \mathrm{mM} \mathrm{KCl}, 1.3 \mathrm{mM} \mathrm{NaH}_{2} \mathrm{PO}_{4}$, 
$73126 \mathrm{mM} \mathrm{NaHCO}_{3}, 4 \mathrm{mM} \mathrm{MgCl}$, $0.5 \mathrm{mM} \mathrm{CaCl}_{2}, 20 \mathrm{mM}$ D-glucose, $75 \mathrm{mM}$ sucrose and $0.5 \mathrm{mM}$

732 sodium ascorbate ( 315 mosmol, $\mathrm{pH} 7.4$, saturated with $95 \% \mathrm{O}_{2} / 5 \% \mathrm{CO}_{2}$ ). Brains were removed

733 and sectioned in the cutting solution with a VT1200S vibratome (Leica) to obtain $300 \mu \mathrm{m}$

734 coronal slices. Slices containing primary somatosensory cortex were collected and incubated in

735 a custom-made interface holding chamber saturated with $95 \% \mathrm{O}_{2} / 5 \% \mathrm{CO}_{2}$ at $34^{\circ} \mathrm{C}$ for $30 \mathrm{~min}$

736 and then at room temperature for 20 min to 6 hours until they were transferred to the

737 recording chamber. Prior to moving slices to the recording chamber, $500 \mu$ l of fluorescein

738 labeled WFA solution (200 mg/ml, in oxygenated cutting solution) was dropped on top of slices

739 in holding chamber and incubated for 30-45 min to label perineuronal nets. After the

740 incubation period slices were rinsed 3-4 times with oxygenated cutting solution before

741 transferring to the recording chamber.

742 Recordings were performed on submerged slices in artificial cerebrospinal fluid (ACSF)

743 containing $119 \mathrm{mM} \mathrm{NaCl}, 2.5 \mathrm{mM} \mathrm{KCl}, 1.3 \mathrm{mM} \mathrm{NaH}_{2} \mathrm{PO}_{4}, 26 \mathrm{mM} \mathrm{NaHCO}_{3}, 1.3 \mathrm{mM} \mathrm{MgCl}$, 2.5

$744 \mathrm{mM} \mathrm{CaCl}_{2}, 20 \mathrm{mM} \mathrm{D-glucose}$ and $0.5 \mathrm{mM}$ sodium ascorbate (305 mosmol, pH 7.4, saturated

745 with $95 \% \mathrm{O}_{2} / 5 \% \mathrm{CO}_{2}$, perfused at $3 \mathrm{ml} / \mathrm{min}$ ) at $32^{\circ} \mathrm{C}$. For whole-cell recordings, a $\mathrm{K}^{+}$-based

746 pipette solution containing $142 \mathrm{mM} \mathrm{K}^{+}$-gluconate, $10 \mathrm{mM}$ HEPES, 1 mM EGTA, 2.5 mM MgCl 2,4

747 mM ATP-Mg, 0.3 mM GTP-Na, 10 mM Na2-phosphoCreatine (295 mosmol, pH 7.35) or a Cs+-

748 based pipette solution containing $121 \mathrm{mM} \mathrm{Cs}^{+}$-methanesulfonate, 10 mM HEPES, 10 mM EGTA,

$7491.5 \mathrm{mM} \mathrm{MgCl}$, 4 mM ATP-Mg, 0.3 mM GTP-Na, 10 mM Na2-phosphoCreatine, and 2 mM

750 QX314-Cl (295 mosmol, pH 7.35) was used. Membrane potentials were not corrected for liquid 751 junction potential (experimentally measured as $12.5 \mathrm{mV}$ for the $\mathrm{K}^{+}$-based pipette solution and

$7529.5 \mathrm{mV}$ for the $\mathrm{Cs}^{+}$-based pipette solution).

$753 \quad$ Neurons were visualized with video-assisted infrared differential interference contrast

754 imaging and WFA+ neurons were identified by epifluorescence imaging under a water

755 immersion objective (40x, 0.8 numerical aperture) on an upright SliceScope Pro 1000

756 microscope (Scientifica) with an infrared IR-1000 CCD camera (DAGE-MTI). Data were acquired

757 at $10 \mathrm{kHz}$ and low-pass filtered at $4 \mathrm{kHz}$ with an Axon Multiclamp 700B amplifier and an Axon

758 Digidata 1440 Data Acquisition System under the control of Clampex 10.7 (Molecular Devices). 
Neuronal intrinsic excitability was examined with the $\mathrm{K}^{+}$-based pipette solution. The

resting membrane potential was recorded in the whole-cell current clamp mode within the first minute after break-in. After balancing the bridge, the input resistance and membrane capacitance were measured by injecting a 500-ms hyperpolarizing current pulse (50-100 pA) to generate a small membrane potential hyperpolarization $(2-10 \mathrm{mV})$ from the resting membrane potential. Depolarizing currents were increased in 5- or 10-pA steps to identify rheobase currents. To generate the current-firing frequency curves, the resting membrane potential of neurons was held at $-75 \mathrm{mV}$ and $500-\mathrm{ms}$ depolarizing current pulses were increased by $50 \mathrm{pA}$ steps from 0 to $1450 \mathrm{pA}$. If depolarization block occurred prior to $1450 \mathrm{pA}$, then recording was

768 stopped.

To record miniature synaptic currents, whole-cell voltage clamp recordings of WFA+ cells were performed with the $\mathrm{Cs}^{+}$-based pipette solution in ACSF containing $1 \mu \mathrm{M}$ tetrodotoxin. mEPSCs and mIPSCs were recorded for 2-3 min at the reversal potential for inhibition ( $-70 \mathrm{mV})$

772 and excitation (+10 $\mathrm{mV})$, respectively.

Electrophysiology data analysis. Data were analyzed offline by AxoGraph X (AxoGraph

775 Scientific). The single action potential generated by the rheobase current was used to analyze

776 action potential characteristics. Action potential threshold was defined as the voltage at which

777 the first derivative of voltage over time exceeded $20 \mathrm{~V} / \mathrm{s}$. The action potential latency was

778 determined as the time between the onset of current injection and action potential threshold.

779 Action potential amplitude was determined as the voltage difference between the action

780 potential threshold and peak. Action potential half-width was measured as the duration of the

781 action potential at the voltage halfway between the action potential threshold and peak.

782 Afterhyperpolarization (AHP) amplitude was determined as the minimum voltage following the 783 action potential peak subtracted from the action potential threshold. AHP time was determined 784 as the time between action potential threshold and the negative peak of AHP.

To analyze spike trains, action potentials were detected using Axograph X event 786 detection with a fixed amplitude template defined by the shape of the action potential. The 787 current-firing frequency curves were generated by measuring the frequency of action 
potentials for each current injection. Spike frequency adaptation and amplitude adaptation were determined from the spike train evoked by the currents that are 2 times of the action potential threshold currents. Spike frequency adaptation was measured by determining the 791 percent decrease between the inverse of the average of the first five inter-spike intervals and

792 the inverse of the average of the last five inter-spike intervals. Amplitude adaptation was

793 determined by baselining the trace at the action potential threshold for the first action

794 potential and then calculating the percent decrease between the amplitude of the first action

795 potential and the last one. The firing frequency within the first $100 \mathrm{~ms}$ of current injection was

796 also determined. Depolarization block current was determined as the minimal current that

797 caused the cell to reach depolarization block during the 500 ms current pulse. If depolarization

798 block was not reached by 1450 pA current injection, 1450 pA was recorded as the value.

799 To detect miniature synaptic events, data were digitally low-pass filtered at $2 \mathrm{kHz}$ offline 800 and events were detected by a scaled-template algorithm (AxoGraph X). The parameters of the 801 template for mEPSCs are: length, $5 \mathrm{~ms}$; baseline, $1.5 \mathrm{~ms}$; amplitude, $-2 \mathrm{pA}$; rise time, $0.2 \mathrm{~ms}$; 802 and decay time, $1 \mathrm{~ms}$ with a detection threshold of -3.25 . The parameters of the template for 803 mIPSCs are: length, $10 \mathrm{~ms}$; baseline, $3 \mathrm{~ms}$; amplitude, 2 pA; rise time, $0.27 \mathrm{~ms}$; and decay time, $8043.7 \mathrm{~ms}$ with a detection threshold of 3 . The integrated charge per unit time for mEPSC or mIPSC 805 was determined by multiplying the frequency of mEPSC or mIPSC by the average charge of 806 mEPSCs or mIPSCs, respectively.

Statistical Analyses. No statistical methods were used to pre-determine sample sizes, but our sample sizes are similar to those previously reported(Chiang et al., 2018; Ho et al., 2014). Sets of age-matched conditional knockout mice and their controls were randomly collected from the

811 same litter or from two litters that had close dates of birth. Data were collected and processed 812 randomly and were analyzed using Microsoft Excel and GraphPad Prism. Except for

813 perineuronal net quantifications, researchers were not 'blinded' to the conditions of the 814 experiments for data collection and analysis. Unless otherwise stated, unpaired, two-tailed 815 Student's $t$-test was used for statistical analysis. Data distributions were assumed to be normal, 
816 but were not formally tested. All error bars are SEM unless otherwise indicated. Significance

817 values indicated in figures are for post hoc comparisons.

\section{REFERENCES}

821 Aberg, K.A., Liu, Y., Bukszar, J., McClay, J.L., Khachane, A.N., Andreassen, O.A., Blackwood, D.,

822 Corvin, A., Djurovic, S., Gurling, H., et al. (2013). A comprehensive family-based replication

823 study of schizophrenia genes. JAMA Psychiatry 70, 573-581.

824 Amor, V., Zhang, C., Vainshtein, A., Zhang, A., Zollinger, D.R., Eshed-Eisenbach, Y., Brophy, P.J.,

825 Rasband, M.N., and Peles, E. (2017). The paranodal cytoskeleton clusters $\mathrm{Na}(+)$ channels at

826 nodes of Ranvier. eLife 6.

827 Bekku, Y., Rauch, U., Ninomiya, Y., and Oohashi, T. (2009). Brevican distinctively assembles

828 extracellular components at the large diameter nodes of Ranvier in the CNS. J Neurochem 108,

829 1266-1276.

830 Bennett, V., and Lorenzo, D.N. (2013). Spectrin- and ankyrin-based membrane domains and the 831 evolution of vertebrates. Current topics in membranes 72, 1-37.

832 Bennett, V., and Stenbuck, P.J. (1979). The membrane attachment protein for spectrin is 833 associated with band 3 in human erythrocyte membranes. Nature 280, 468-473.

834 Berretta, S. (2012). Extracellular matrix abnormalities in schizophrenia. Neuropharmacology 62, 835 1584-1597.

836 Boda, E., Hoxha, E., Pini, A., Montarolo, F., and Tempia, F. (2012). Brain expression of Kv3 837 subunits during development, adulthood and aging and in a murine model of Alzheimer's 838 disease. J Mol Neurosci 46, 606-615.

839 Bruckner, G., Brauer, K., Hartig, W., Wolff, J.R., Rickmann, M.J., Derouiche, A., Delpech, B., 840 Girard, N., Oertel, W.H., and Reichenbach, A. (1993). Perineuronal nets provide a polyanionic, 841 glia-associated form of microenvironment around certain neurons in many parts of the rat 842 brain. Glia 8, 183-200. 
843 Cabungcal, J.H., Steullet, P., Morishita, H., Kraftsik, R., Cuenod, M., Hensch, T.K., and Do, K.Q.

844 (2013). Perineuronal nets protect fast-spiking interneurons against oxidative stress. Proc Natl

845 Acad Sci U S A 110, 9130-9135.

846 Carceller, H., Guirado, R., Ripolles-Campos, E., Teruel-Marti, V., and Nacher, J. (2020).

847 Perineuronal Nets Regulate the Inhibitory Perisomatic Input onto Parvalbumin Interneurons

848 and gamma Activity in the Prefrontal Cortex. J Neurosci 40, 5008-5018.

849 Carulli, D., Rhodes, K.E., and Fawcett, J.W. (2007). Upregulation of aggrecan, link protein 1, and

850 hyaluronan synthases during formation of perineuronal nets in the rat cerebellum. J Comp

851 Neurol 501, 83-94.

852 Chang, K.J., Zollinger, D.R., Susuki, K., Sherman, D.L., Makara, M.A., Brophy, P.J., Cooper, E.C.,

853 Bennett, V., Mohler, P.J., and Rasband, M.N. (2014). Glial ankyrins facilitate paranodal axoglial

854 junction assembly. Nat Neurosci 17, 1673-1681.

855 Chang, S.Y., Zagha, E., Kwon, E.S., Ozaita, A., Bobik, M., Martone, M.E., Ellisman, M.H., Heintz,

856 N., and Rudy, B. (2007). Distribution of Kv3.3 potassium channel subunits in distinct neuronal

857 populations of mouse brain. J Comp Neurol 502, 953-972.

858 Chiang, A.C.A., Fowler, S.W., Reddy, R., Pletnikova, O., Troncoso, J.C., Sherman, M.A., Lesne,

859 S.E., and Jankowsky, J.L. (2018). Discrete Pools of Oligomeric Amyloid-beta Track with Spatial

860 Learning Deficits in a Mouse Model of Alzheimer Amyloidosis. Am J Pathol 188, 739-756.

861 Clauser, K.R., Baker, P., and Burlingame, A.L. (1999). Role of accurate mass measurement (+/-

$86210 \mathrm{ppm}$ ) in protein identification strategies employing MS or MS/MS and database searching.

863 Anal Chem 71, 2871-2882.

864 Coetzer, T.L., Lawler, J., Liu, S.C., Prchal, J.T., Gualtieri, R.J., Brain, M.C., Dacie, J.V., and Palek, J.

865 (1988). Partial ankyrin and spectrin deficiency in severe, atypical hereditary spherocytosis. $\mathrm{N}$

866 Engl J Med 318, 230-234.

867 Crapser, J.D., Spangenberg, E.E., Barahona, R.A., Arreola, M.A., Hohsfield, L.A., and Green, K.N.

868 (2020). Microglia facilitate loss of perineuronal nets in the Alzheimer's disease brain.

869 EBioMedicine 58, 102919. 
870 Davis, J.Q., and Bennett, V. (1994). Ankyrin binding activity shared by the

871 neurofascin/L1/NrCAM family of nervous system cell adhesion molecules. J Biol Chem 269,

$872 \quad 27163-27166$.

873 De Jager, P.L., Srivastava, G., Lunnon, K., Burgess, J., Schalkwyk, L.C., Yu, L., Eaton, M.L., Keenan,

874 B.T., Ernst, J., McCabe, C., et al. (2014). Alzheimer's disease: early alterations in brain DNA

875 methylation at ANK1, BIN1, RHBDF2 and other loci. Nat Neurosci 17, 1156-1163.

876 de Lombares, C., Heude, E., Alfama, G., Fontaine, A., Hassouna, R., Vernochet, C., de Chaumont,

877 F., Olivo-Marin, C., Ey, E., Parnaudeau, S., et al. (2019). Dlx5 and Dlx6 expression in GABAergic

878 neurons controls behavior, metabolism, healthy aging and lifespan. Aging (Albany NY) 11, 6638-

8796656.

880 de Winter, F., Kwok, J.C., Fawcett, J.W., Vo, T.T., Carulli, D., and Verhaagen, J. (2016). The

881 Chemorepulsive Protein Semaphorin 3A and Perineuronal Net-Mediated Plasticity. Neural Plast

$882 \quad 2016,3679545$.

883 Devaux, J., Alcaraz, G., Grinspan, J., Bennett, V., Joho, R., Crest, M., and Scherer, S.S. (2003).

$884 \mathrm{Kv3} .1 \mathrm{~b}$ is a novel component of CNS nodes. J Neurosci 23, 4509-4518.

885 Dzhashiashvili, Y., Zhang, Y., Galinska, J., Lam, I., Grumet, M., and Salzer, J.L. (2007). Nodes of

886 Ranvier and axon initial segments are ankyrin G-dependent domains that assemble by distinct

887 mechanisms. J Cell Biol 177, 857-870.

888 Favuzzi, E., Marques-Smith, A., Deogracias, R., Winterflood, C.M., Sanchez-Aguilera, A.,

889 Mantoan, L., Maeso, P., Fernandes, C., Ewers, H., and Rico, B. (2017). Activity-Dependent Gating

890 of Parvalbumin Interneuron Function by the Perineuronal Net Protein Brevican. Neuron 95,

$891 \quad 639-655$ e610.

892 Fawcett, J.W., Oohashi, T., and Pizzorusso, T. (2019). The roles of perineuronal nets and the

893 perinodal extracellular matrix in neuronal function. Nat Rev Neurosci 20, 451-465.

894 Fromer, M., Pocklington, A.J., Kavanagh, D.H., Williams, H.J., Dwyer, S., Gormley, P., Georgieva,

895 L., Rees, E., Palta, P., Ruderfer, D.M., et al. (2014). De novo mutations in schizophrenia implicate 896 synaptic networks. Nature 506, 179-184. 
897 Garrido, J.J., Giraud, P., Carlier, E., Fernandes, F., Moussif, A., Fache, M.P., Debanne, D., and

898 Dargent, B. (2003). A targeting motif involved in sodium channel clustering at the axonal initial

899 segment. Science 300, 2091-2094.

900 Garver, T.D., Ren, Q., Tuvia, S., and Bennett, V. (1997). Tyrosine phosphorylation at a site highly

901 conserved in the L1 family of cell adhesion molecules abolishes ankyrin binding and increases

902 lateral mobility of neurofascin. J Cell Biol 137, 703-714.

903 Gasparoni, G., Bultmann, S., Lutsik, P., Kraus, T.F.J., Sordon, S., Vlcek, J., Dietinger, V.,

904 Steinmaurer, M., Haider, M., Mulholland, C.B., et al. (2018). DNA methylation analysis on

905 purified neurons and glia dissects age and Alzheimer's disease-specific changes in the human

906 cortex. Epigenetics Chromatin 11, 41.

907 Gottschling, C., Wegrzyn, D., Denecke, B., and Faissner, A. (2019). Elimination of the four

908 extracellular matrix molecules tenascin- $C$, tenascin- $R$, brevican and neurocan alters the ratio of

909 excitatory and inhibitory synapses. Scientific reports 9, 13939.

910 Guan, S., Price, J.C., Prusiner, S.B., Ghaemmaghami, S., and Burlingame, A.L. (2011). A data

911 processing pipeline for mammalian proteome dynamics studies using stable isotope metabolic

912 labeling. Molecular \& cellular proteomics : MCP 10, M111 010728.

913 Hartig, W., Derouiche, A., Welt, K., Brauer, K., Grosche, J., Mader, M., Reichenbach, A., and

914 Bruckner, G. (1999). Cortical neurons immunoreactive for the potassium channel Kv3.1b

915 subunit are predominantly surrounded by perineuronal nets presumed as a buffering system

916 for cations. Brain Res 842, 15-29.

917 Hedstrom, K.L., Ogawa, Y., and Rasband, M.N. (2008). AnkyrinG is required for maintenance of

918 the axon initial segment and neuronal polarity. J Cell Biol 183, 635-640.

919 Hedstrom, K.L., Xu, X., Ogawa, Y., Frischknecht, R., Seidenbecher, C.I., Shrager, P., and Rasband,

920 M.N. (2007). Neurofascin assembles a specialized extracellular matrix at the axon initial

921 segment. J Cell Biol 178, 875-886.

922 Higham, J.P., Malik, B.R., Buhl, E., Dawson, J.M., Ogier, A.S., Lunnon, K., and Hodge, J.J.L. (2019).

923 Alzheimer's Disease Associated Genes Ankyrin and Tau Cause Shortened Lifespan and Memory

924 Loss in Drosophila. Frontiers in cellular neuroscience 13, 260. 
925 Ho, T.S., Zollinger, D.R., Chang, K.J., Xu, M., Cooper, E.C., Stankewich, M.C., Bennett, V., and

926 Rasband, M.N. (2014). A hierarchy of ankyrin-spectrin complexes clusters sodium channels at

927 nodes of Ranvier. Nat Neurosci 17, 1664-1672.

928 Huang, C.Y., Zhang, C., Ho, T.S., Oses-Prieto, J., Burlingame, A.L., Lalonde, J., Noebels, J.L.,

929 Leterrier, C., and Rasband, M.N. (2017a). alphall Spectrin Forms a Periodic Cytoskeleton at the

930 Axon Initial Segment and Is Required for Nervous System Function. J Neurosci 37, 11311-11322.

931 Huang, C.Y., Zhang, C., Zollinger, D.R., Leterrier, C., and Rasband, M.N. (2017b). An alphall

932 Spectrin-Based Cytoskeleton Protects Large-Diameter Myelinated Axons from Degeneration. J

933 Neurosci 37, 11323-11334.

934 Irvine, S.F., and Kwok, J.C.F. (2018). Perineuronal Nets in Spinal Motoneurones: Chondroitin

935 Sulphate Proteoglycan around Alpha Motoneurones. Int J Mol Sci 19.

936 Kordeli, E., and Bennett, V. (1991). Distinct ankyrin isoforms at neuron cell bodies and nodes of

937 Ranvier resolved using erythrocyte ankyrin-deficient mice. J Cell Biol 114, 1243-1259.

938 Kwok, J.C., Dick, G., Wang, D., and Fawcett, J.W. (2011). Extracellular matrix and perineuronal

939 nets in CNS repair. Dev Neurobiol 71, 1073-1089.

940 Lau, D., Vega-Saenz de Miera, E.C., Contreras, D., Ozaita, A., Harvey, M., Chow, A., Noebels, J.L.,

941 Paylor, R., Morgan, J.I., Leonard, C.S., and Rudy, B. (2000). Impaired fast-spiking, suppressed

942 cortical inhibition, and increased susceptibility to seizures in mice lacking Kv3.2 K+ channel

943 proteins. J Neurosci 20, 9071-9085.

944 Liu, C.H., Seo, R., Ho, T.S., Stankewich, M., Mohler, P.J., Hund, T.J., Noebels, J.L., and Rasband,

945 M.N. (2020a). beta spectrin-dependent and domain specific mechanisms for $\mathrm{Na}(+)$ channel

946 clustering. elife 9.

947 Liu, C.H., Stevens, S.R., Teliska, L.H., Stankewich, M., Mohler, P.J., Hund, T.J., and Rasband, M.N.

948 (2020b). Nodal beta spectrins are required to maintain $\mathrm{Na}(+)$ channel clustering and axon

949 integrity. eLife 9.

950 Lunnon, K., Smith, R., Hannon, E., De Jager, P.L., Srivastava, G., Volta, M., Troakes, C., Al-Sarraj,

951 S., Burrage, J., Macdonald, R., et al. (2014). Methylomic profiling implicates cortical

952 deregulation of ANK1 in Alzheimer's disease. Nat Neurosci 17, 1164-1170. 
953 Luo, L., Ambrozkiewicz, M.C., Benseler, F., Chen, C., Dumontier, E., Falkner, S., Furlanis, E.,

954 Gomez, A.M., Hoshina, N., Huang, W.H., et al. (2020). Optimizing Nervous System-Specific Gene

955 Targeting with Cre Driver Lines: Prevalence of Germline Recombination and Influencing Factors.

956 Neuron 106, 37-65 e35.

957 Lux, S.E., Tse, W.T., Menninger, J.C., John, K.M., Harris, P., Shalev, O., Chilcote, R.R., Marchesi,

958 S.L., Watkins, P.C., Bennett, V., and et al. (1990). Hereditary spherocytosis associated with

959 deletion of human erythrocyte ankyrin gene on chromosome 8. Nature 345, 736-739.

960 Mauney, S.A., Athanas, K.M., Pantazopoulos, H., Shaskan, N., Passeri, E., Berretta, S., and Woo,

961 T.U. (2013). Developmental pattern of perineuronal nets in the human prefrontal cortex and

962 their deficit in schizophrenia. Biological psychiatry 74, 427-435.

963 McCann, S.R., and Jacob, H.S. (1976). Spinal cord disease in hereditary spherocytosis: report of

964 two cases with a hypothesized common mechanism for neurologic and red cell abnormalities.

965 Blood 48, 259-263.

966 McCloy, R.A., Rogers, S., Caldon, C.E., Lorca, T., Castro, A., and Burgess, A. (2014). Partial

967 inhibition of Cdk1 in G 2 phase overrides the SAC and decouples mitotic events. Cell Cycle 13,

$968 \quad 1400-1412$.

969 Michaely, P., and Bennett, V. (1995). Mechanism for binding site diversity on ankyrin.

970 Comparison of binding sites on ankyrin for neurofascin and the $\mathrm{Cl}$-/HCO3- anion exchanger. J

971 Biol Chem 270, 31298-31302.

972 Miya, K., Shimojima, K., Sugawara, M., Shimada, S., Tsuri, H., Harai-Tanaka, T., Nakaoka, S.,

973 Kanegane, H., Miyawaki, T., and Yamamoto, T. (2012). A de novo interstitial deletion of 8p11.2

974 including ANK1 identified in a patient with spherocytosis, psychomotor developmental delay,

975 and distinctive facial features. Gene 506, 146-149.

976 Miyata, S., Nishimura, Y., and Nakashima, T. (2007). Perineuronal nets protect against amyloid

977 beta-protein neurotoxicity in cultured cortical neurons. Brain Res 1150, 200-206.

978 Murthy, S., Kane, G.A., Katchur, N.J., Lara Mejia, P.S., Obiofuma, G., Buschman, T.J., McEwen,

979 B.S., and Gould, E. (2019). Perineuronal Nets, Inhibitory Interneurons, and Anxiety-Related

980 Ventral Hippocampal Neuronal Oscillations Are Altered by Early Life Adversity. Biological

981 psychiatry 85, 1011-1020. 
982 Nakamura, F., Kalb, R.G., and Strittmatter, S.M. (2000). Molecular basis of semaphorin-

983 mediated axon guidance. J Neurobiol 44, 219-229.

984 Ohira, K., Takeuchi, R., Iwanaga, T., and Miyakawa, T. (2013). Chronic fluoxetine treatment 985 reduces parvalbumin expression and perineuronal nets in gamma-aminobutyric acidergic 986 interneurons of the frontal cortex in adult mice. Mol Brain 6, 43.

987 Pan, Z., Kao, T., Horvath, Z., Lemos, J., Sul, J.-Y., Cranstoun, S.D., Bennett, M.V., Scherer, S.S., 988 and Cooper, E.C. (2006). A common ankyrin-G-based mechanism retains KCNQ and Nav 989 channels at electrically active domains of the axon. J Neurosci 26, 2599-2613.

990 Peters, L.L., Birkenmeier, C.S., Bronson, R.T., White, R.A., Lux, S.E., Otto, E., Bennett, V., Higgins, 991 A., and Barker, J.E. (1991). Purkinje cell degeneration associated with erythroid ankyrin 992 deficiency in nb/nb mice. J Cell Biol 114, 1233-1241.

993 Rowlands, D., Lensjo, K.K., Dinh, T., Yang, S., Andrews, M.R., Hafting, T., Fyhn, M., Fawcett, J.W., 994 and Dick, G. (2018). Aggrecan Directs Extracellular Matrix-Mediated Neuronal Plasticity. J

995 Neurosci 38, 10102-10113.

996 Schizophrenia Working Group of the Psychiatric Genomics, C. (2014). Biological insights from 997108 schizophrenia-associated genetic loci. Nature 511, 421-427.

998 Scotland, P., Zhou, D., Benveniste, H., and Bennett, V. (1998). Nervous system defects of

999 AnkyrinB (-/-) mice suggest functional overlap between the cell adhesion molecule L1 and 440-

1000 kD AnkyrinB in premyelinated axons. J Cell Biol 143, 1305-1315.

1001 Sedgwick, S.G., and Smerdon, S.J. (1999). The ankyrin repeat: a diversity of interactions on a 1002 common structural framework. Trends Biochem Sci 24, 311-316.

1003 Smith, A.R., Smith, R.G., Burrage, J., Troakes, C., Al-Sarraj, S., Kalaria, R.N., Sloan, C., Robinson, 1004 A.C., Mill, J., and Lunnon, K. (2019a). A cross-brain regions study of ANK1 DNA methylation in 1005 different neurodegenerative diseases. Neurobiology of aging 74, 70-76.

1006 Smith, A.R., Smith, R.G., Pishva, E., Hannon, E., Roubroeks, J.A.Y., Burrage, J., Troakes, C., Al-

1007 Sarraj, S., Sloan, C., Mill, J., et al. (2019b). Parallel profiling of DNA methylation and

1008 hydroxymethylation highlights neuropathology-associated epigenetic variation in Alzheimer's 1009 disease. Clin Epigenetics 11, 52. 
1010 Susuki, K., Chang, K.J., Zollinger, D.R., Liu, Y., Ogawa, Y., Eshed-Eisenbach, Y., Dours-

1011 Zimmermann, M.T., Oses-Prieto, J.A., Burlingame, A.L., Seidenbecher, C.I., et al. (2013). Three

1012 mechanisms assemble central nervous system nodes of Ranvier. Neuron 78, 469-482.

1013 Susuki, K., Zollinger, D.R., Chang, K.J., Zhang, C., Huang, C.Y., Tsai, C.R., Galiano, M.R., Liu, Y.,

1014 Benusa, S.D., Yermakov, L.M., et al. (2018). Glial betall Spectrin Contributes to Paranode

1015 Formation and Maintenance. J Neurosci 38, 6063-6075.

1016 Suttkus, A., Holzer, M., Morawski, M., and Arendt, T. (2016a). The neuronal extracellular matrix 1017 restricts distribution and internalization of aggregated Tau-protein. Neuroscience 313, 225-235.

1018 Suttkus, A., Morawski, M., and Arendt, T. (2016b). Protective Properties of Neural Extracellular 1019 Matrix. Mol Neurobiol 53, 73-82.

1020 Tuvia, S., Garver, T.D., and Bennett, V. (1997). The phosphorylation state of the FIGQY tyrosine 1021 of neurofascin determines ankyrin-binding activity and patterns of cell segregation. Proc Natl 1022 Acad Sci U S A 94, 12957-12962.

1023 Wang, C.C., Ortiz-Gonzalez, X.R., Yum, S.W., Gill, S.M., White, A., Kelter, E., Seaver, L.H., Lee, S., 1024 Wiley, G., Gaffney, P.M., et al. (2018). betalV Spectrinopathies Cause Profound Intellectual 1025 Disability, Congenital Hypotonia, and Motor Axonal Neuropathy. Am J Hum Genet 102, 115810261168.

1027 Wintergerst, E.S., Vogt Weisenhorn, D.M., Rathjen, F.G., Riederer, B.M., Lambert, S., and Celio, 1028 M.R. (1996). Temporal and spatial appearance of the membrane cytoskeleton and perineuronal 1029 nets in the rat neocortex. Neurosci Lett 209, 173-176.

1030 Yamada, J., and Jinno, S. (2017). Molecular heterogeneity of aggrecan-based perineuronal nets 1031 around five subclasses of parvalbumin-expressing neurons in the mouse hippocampus. J Comp 1032 Neurol 525, 1234-1249.

1033 Yanagi, M., Joho, R.H., Southcott, S.A., Shukla, A.A., Ghose, S., and Tamminga, C.A. (2014).

1034 Kv3.1-containing $\mathrm{K}(+)$ channels are reduced in untreated schizophrenia and normalized with 1035 antipsychotic drugs. Molecular psychiatry 19, 573-579.

1036 Zhou, D., Lambert, S., Malen, P.L., Carpenter, S., Boland, L.M., and Bennett, V. (1998). AnkyrinG 1037 is required for clustering of voltage-gated Na channels at axon initial segments and for normal 1038 action potential firing. J Cell Biol 143, 1295-1304. 
bioRxiv preprint doi: https://doi.org/10.1101/2021.0121.427626; this version posted January 21, 2021. The copyright holder for this preprint (which was not certified by peer review) is the author/funder, who has granted bioRxiv a license to display the preprint in perpetuity. It is made available under aCC-BY 4.0 International license.

Figure 1
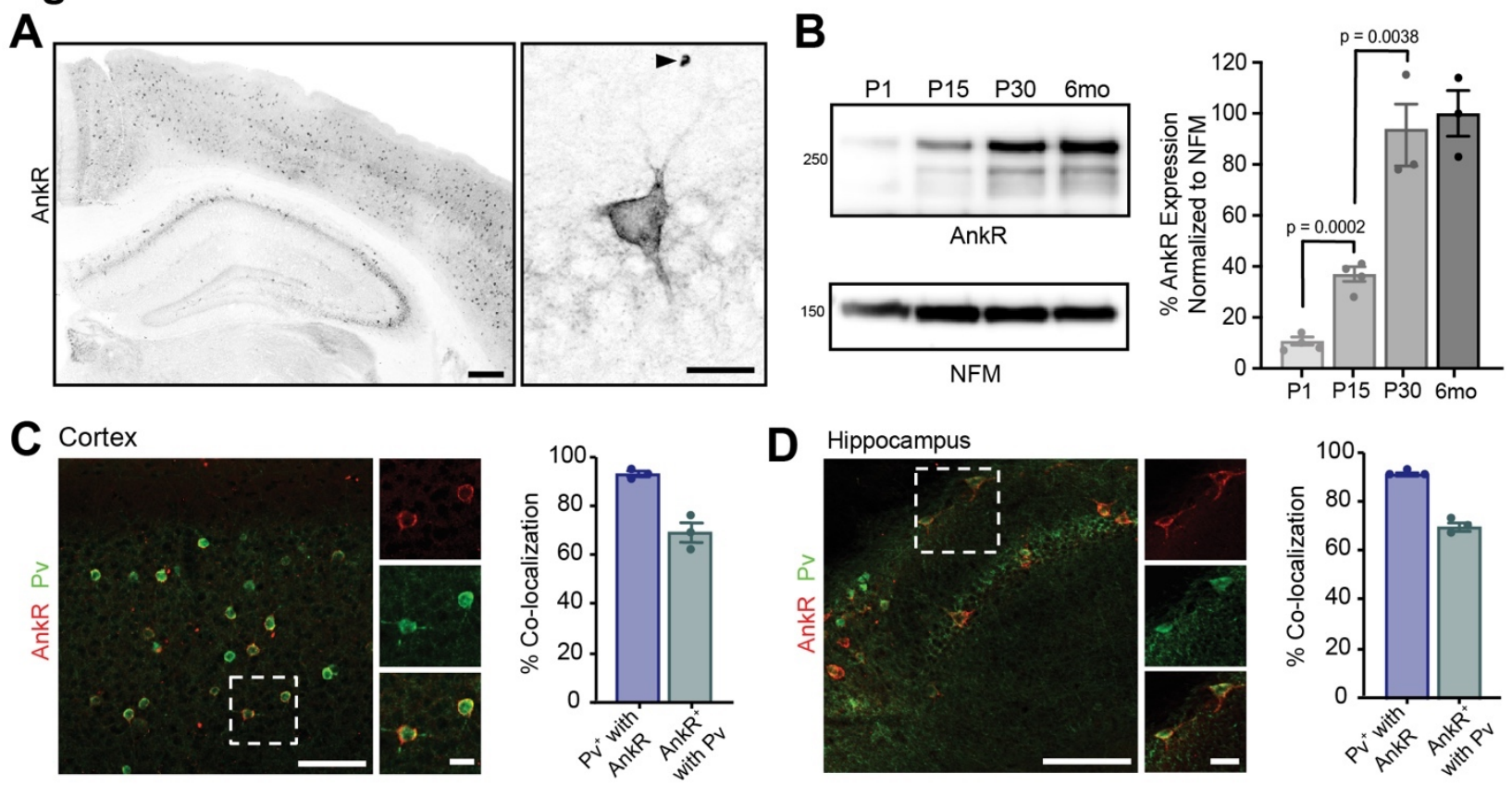

$\mathbf{E}$

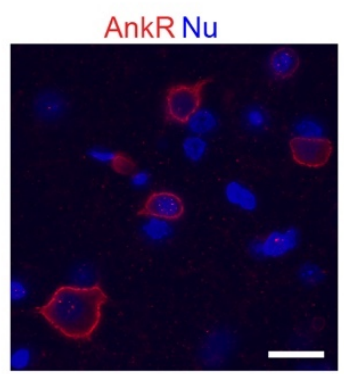

AnkR Pv Nu

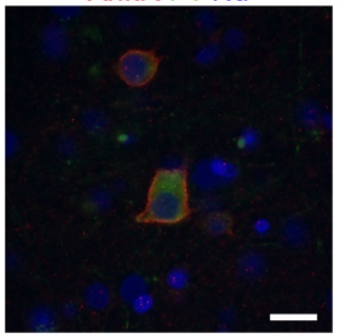

D

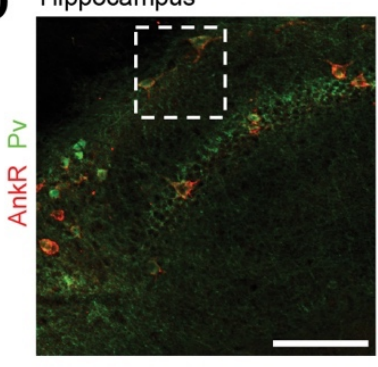

$\mathbf{F}$

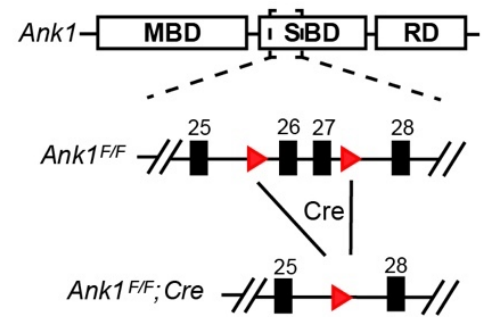

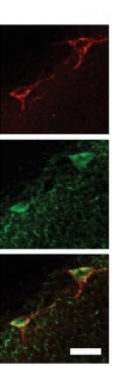

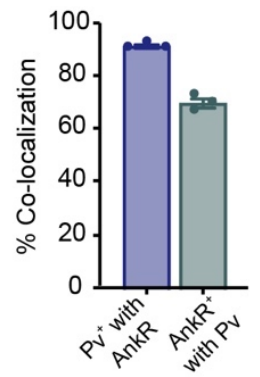

G

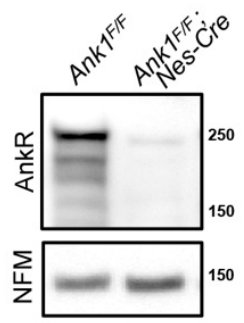


1041 Figure 1. AnkR is expressed in select neurons in the cortex and hippocampus.

1042 (A) Immunostaining of coronal mouse brain for AnkR. Arrowhead indicates a red blood cell.

1043 Scalebars, left, $250 \mu \mathrm{m}$, right, $20 \mu \mathrm{m}$.

1044 (B) Immunoblot of P1, P15, P30, and 6-month C57BL/6 brain homogenates for anti-AnkR and 1045 neurofilament-M (NFM). Quantification of immunoblot in Image by comparison of AnkR to 1046 NFM loading control from three independent duplicate experiments ( $n=3-4$ mice/group).

1047 Samples were normalized to NFM, then compared to 6-month animals.

1048 (C, D) Immunostaining for AnkR (red) and Parvalbumin (Pv, green) in P56 coronal cortex (C, N = 10493 mice; $n=4495$ cells) and coronal hippocampus ( $D, N=3$ mice; $n=1637$ cells). Scalebars, $50 \mu m$; 1050 inset, $10 \mu \mathrm{m}$.

1051 (E) Immunostaining of human cortex for AnkR (red) and Parvalbumin (green). Nuclei are 1052 labeled using DAPI (blue). Scalebars, $20 \mu \mathrm{m}$.

1053 (F) Schematic of the Ank1 conditional allele. loxP sites (red triangles) flank exons 26 and 27 in 1054 the spectrin binding domain (SBD), after the membrane binding domain (MBD) and before the 1055 regulatory domain (RD). Cre-mediated recombination and removal of exons 26 and 27 1056 generates a premature stop codon in exon 28.

1057 (G) Immunoblot of brain homogenates for anti-AnkR, and Neurofilament-M. Molecular weights 1058 are indicated at right in $\mathrm{kDa}$. All error bars indicate mean $\pm \mathrm{SEM}$. 


\section{Supplemental Figure 1}

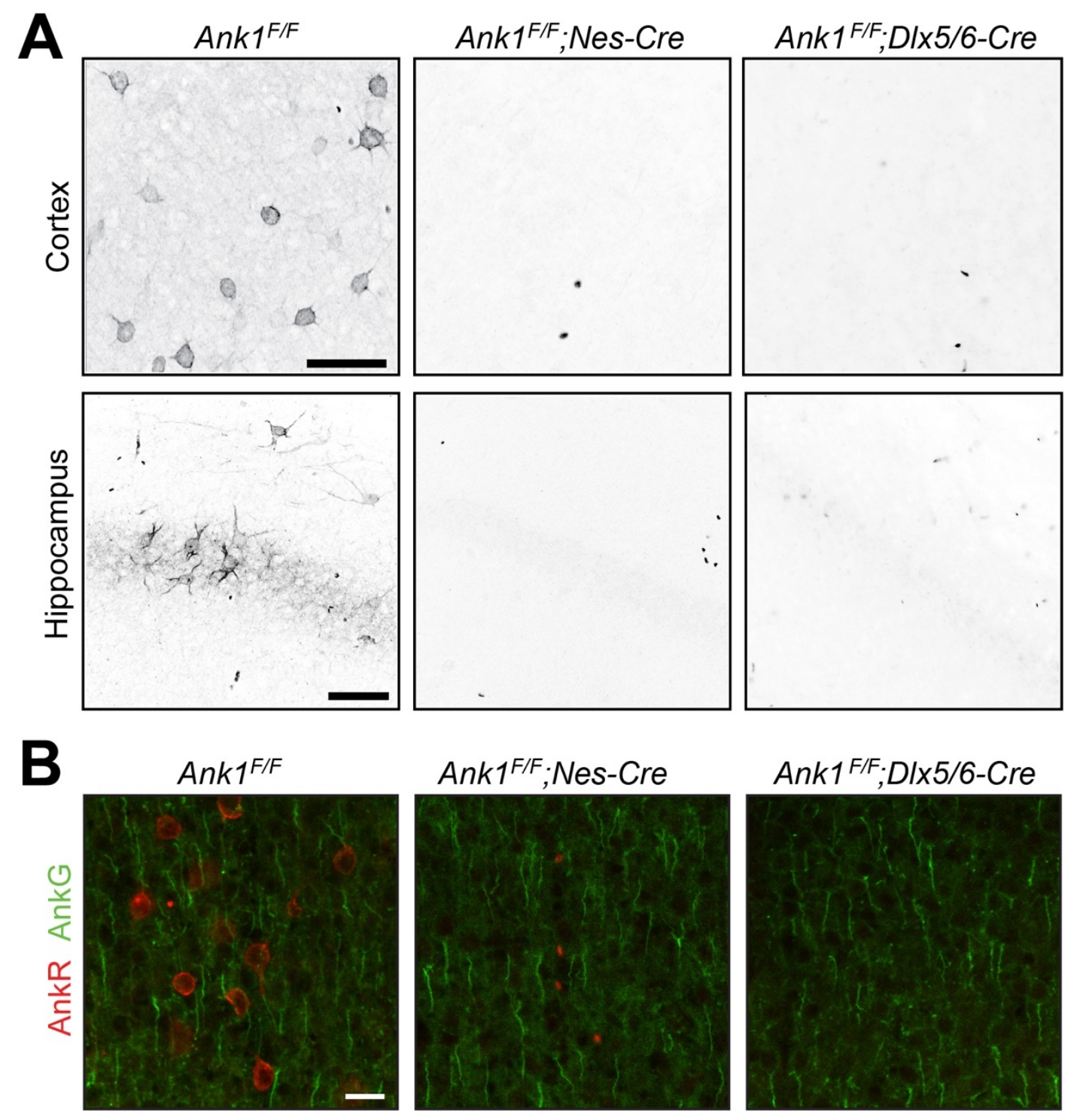

1060 Supplemental Figure 1. AnkR immunostaining in Ank1 conditional knockout mice.

1061 (A) Immunostaining of cortex (top) and hippocampus (bottom) in mice with the indicated 1062 genotypes. Scalebars, $50 \mu \mathrm{m}$.

1063 (B) Immunostaining of cortex for AnkR (red) and AnkG (green) in the indicated genotypes. 1064 Scalebars, $20 \mu \mathrm{m}$. 
bioRxiv preprint doi: https://doi.org/10.1101/2021.01.21.427626; this version posted January 21, 2021. The copyright holder for this preprint (which was not certified by peer review) is the author/funder, who has granted bioRxiv a license to display the preprint in perpetuity. It is made available under aCC-BY 4.0 International license.

Figure 2
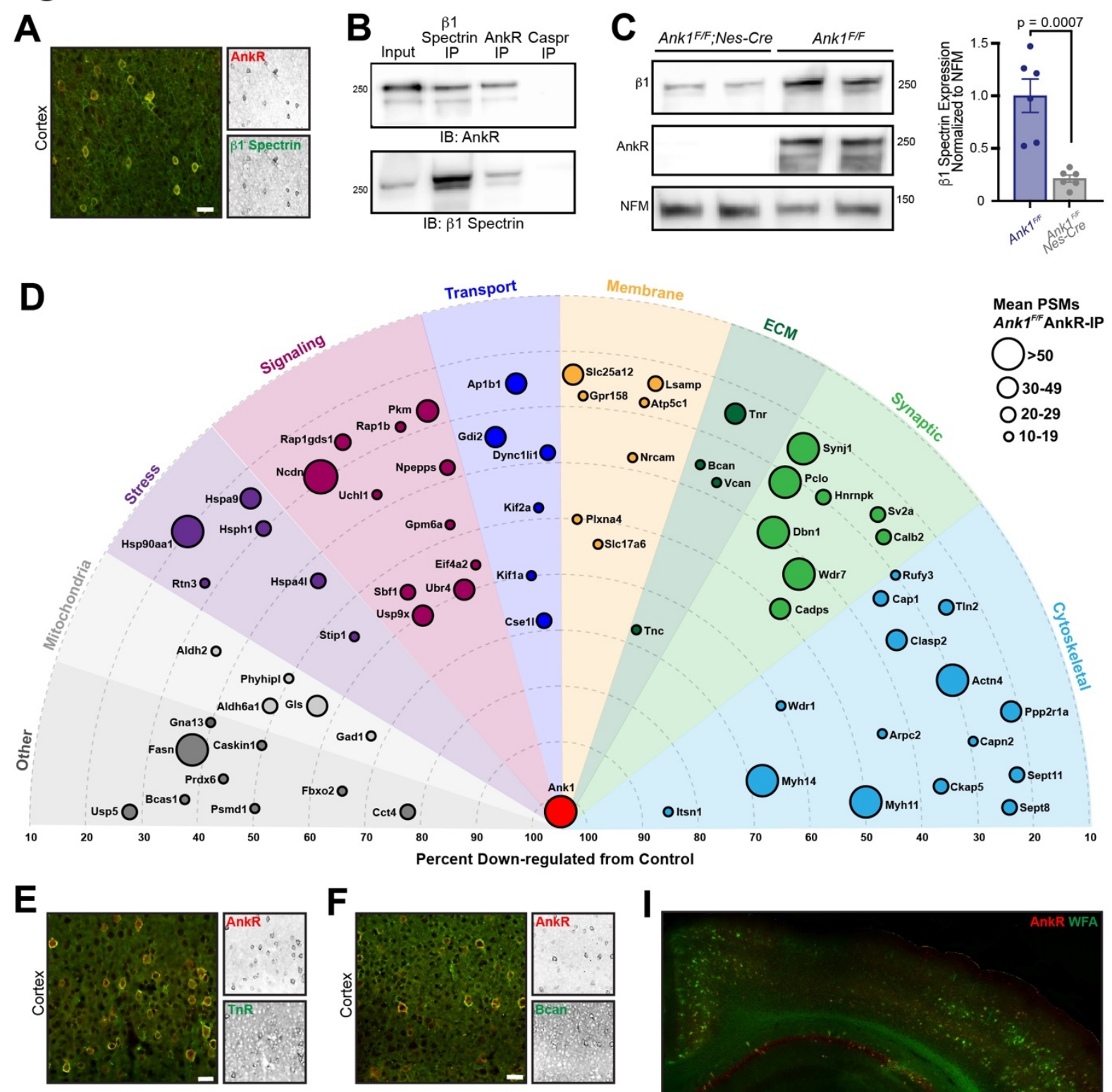

\section{G}

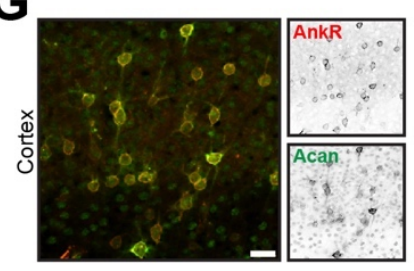

H
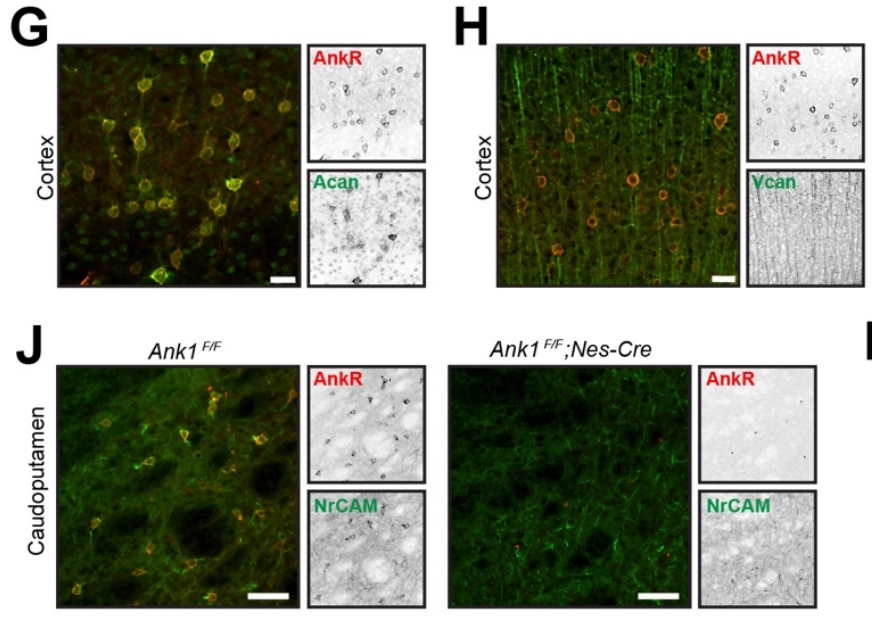

Ank1 ${ }^{\text {FF }}$;Nes-Cre

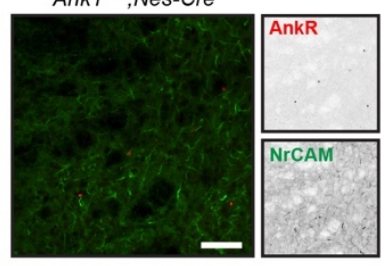

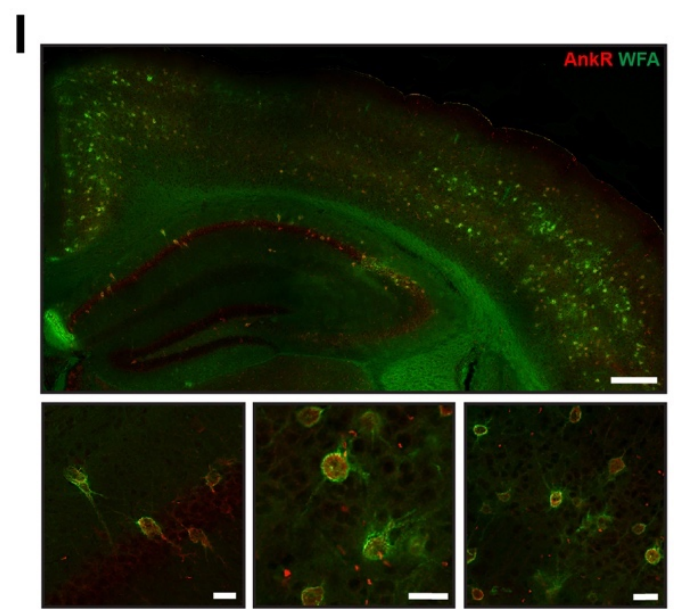

K

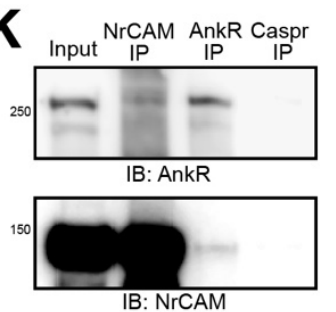

$L_{\text {Input }}^{\text {PlexinA4 AnkR Caspr }}$

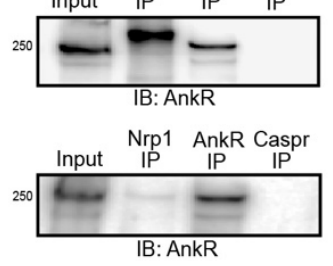


1067 Figure 2. AnkR interacting proteins.

1068 (A) Immunostaining of mouse cortex using antibodies against AnkR (red) and $\beta 1$ spectrin 1069 (green). Scalebar, $20 \mu \mathrm{m}$.

1070 (B) Immunoblot of $\beta 1$ spectrin, AnkR, and Caspr immunoprecipitation reactions using

1071 antibodies against AnkR and $\beta 1$ spectrin. IP, immunoprecipitation; IB, immunoblot.

1072 (C) Immunoblot of control and AnkR-deficient mouse brains using antibodies against $\beta 1$

1073 spectrin, AnkR, and neurofilament-M (NFM). Quantification of the $\beta 1$ spectrin immunoblots 1074 normalized to NFM. Error bars indicate mean \pm SEM. $N=6$.

1075 (D) Top AnkR-interacting candidates. Circle size corresponds to the mean PSM from IP mass 1076 spectrometry. Concentric circles radiating from Ank1 correspond to \% reduction in PSMs from 1077 AnkR knockout mouse compared to control. Identified proteins are organized according to 1078 their putative functions.

1079 (E-H) Immunostaining of mouse cortex using antibodies against AnkR (red) and TnR (green, E), 1080 Bcan (green, F), Acan (green, G), and Vcan (green, H). Scalebars, $20 \mu \mathrm{m}$.

1081 (I) Immunostaining of mouse cortex and hippocampus using antibodies against AnkR (red) and 1082 fluorescent-labeled WFA (green). Scalebars, $250 \mu \mathrm{m}$ (top) and $20 \mu \mathrm{m}$ (bottom).

1083 (J) Immunostaining of control (left) and AnkR-deficient mouse brain (right) using antibodies 1084 against AnkR (red) and NrCAM (green). Scalebars, $50 \mu \mathrm{m}$.

1085 (K) Immunoblot of NrCAM, AnkR, and Caspr immunoprecipitation reactions using antibodies 1086 against AnkR (top) and NrCAM (bottom).

1087 (L) Immunoblot of PlexinA4, AnkR, and Caspr immunoprecipitation reactions using antibodies 1088 against AnkR (top). Immunoblot of Nrp1, AnkR, and Caspr immunoprecipitation reactions using 1089 antibodies against AnkR (bottom). 


\section{Supplemental Figure 2}
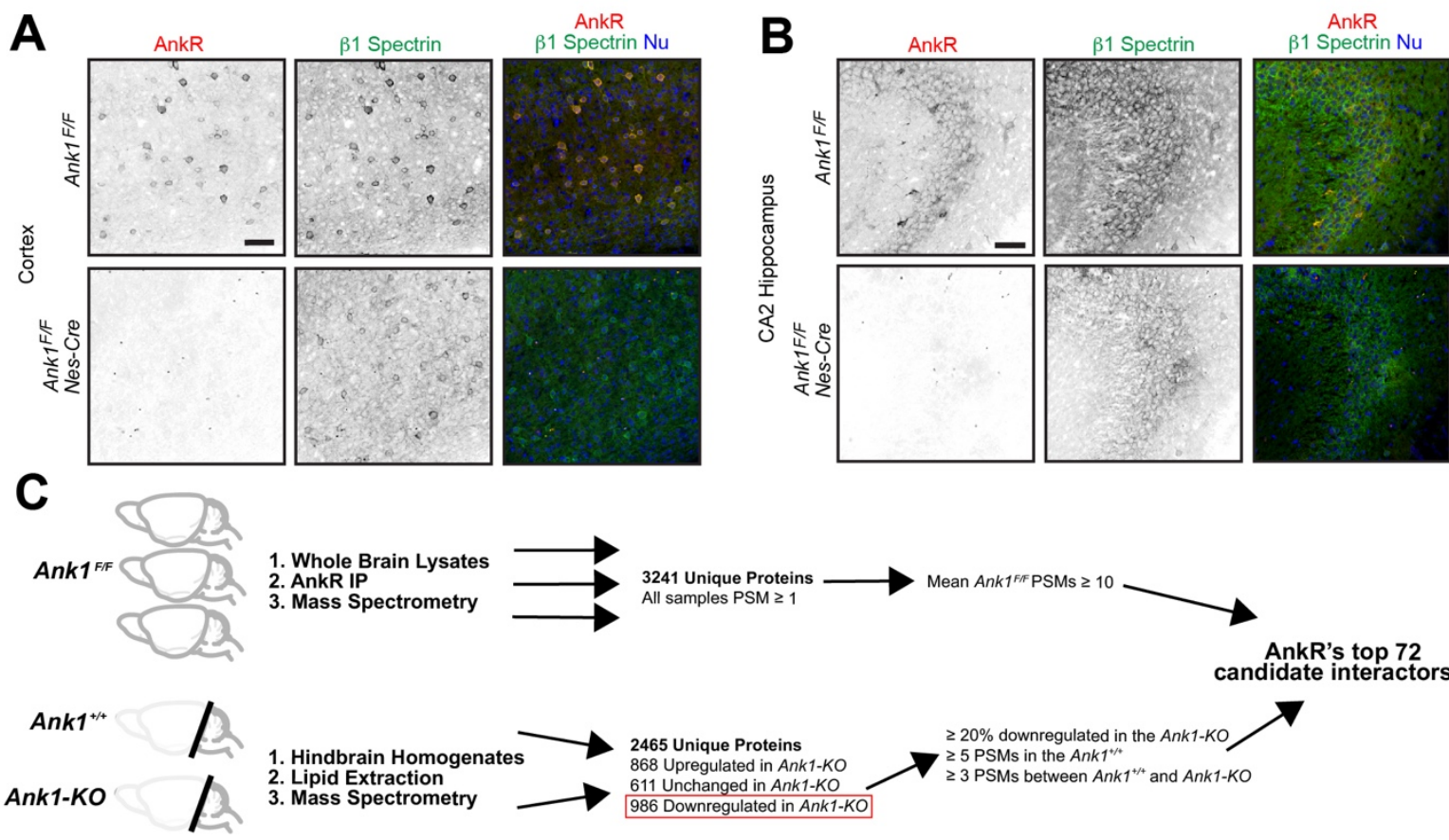

1. Whole Brain Lysates 2. AnkR IP 3. Mass Spectrometry

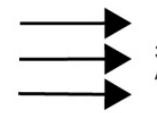
3241 Unique Proteins
All samples $P S M \geq 1$

Mean Ank $1^{\text {FFF PSMs }} \geq 10$

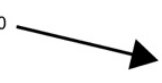

AnkR's top 72 candidate interactors

D

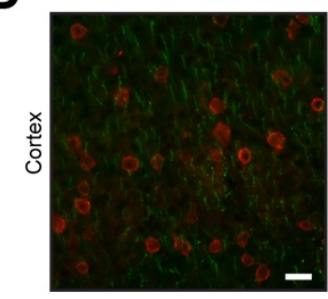

G
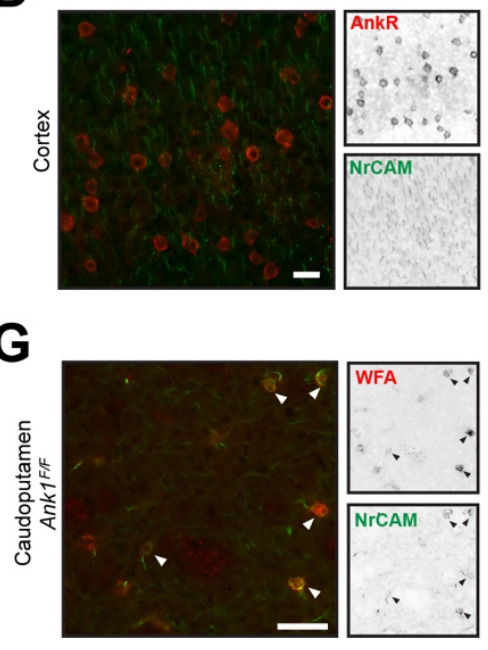

E

1. Hindbrain Homogenates 2. Lipid Extraction Mass Spectrometry

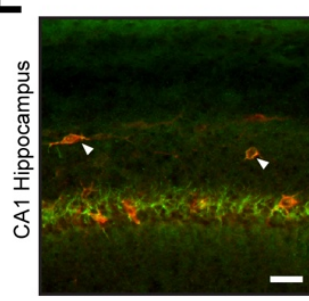

H

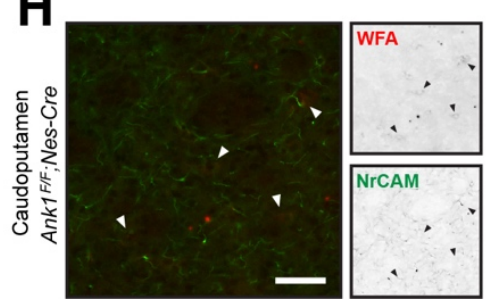

F
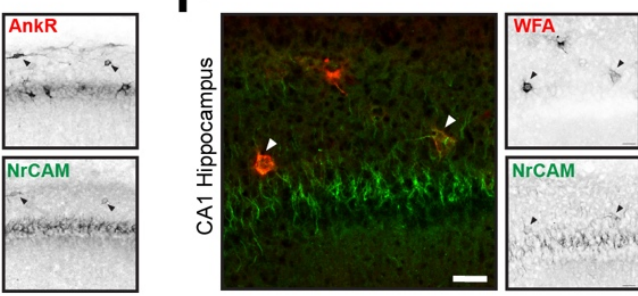

I
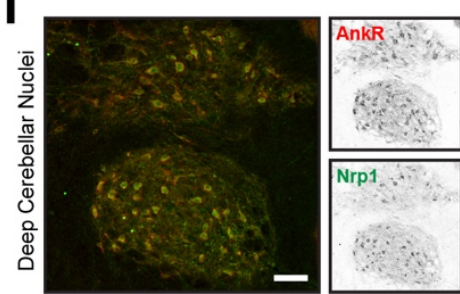
1092 Supplemental Figure 2. AnkR interacting proteins.

1093 (A, B) Immunostaining of cortex (A) and hippocampus (B) in control and AnkR-deficient mouse 1094 brain using antibodies against AnkR (red), $\beta 1$ spectrin (green), and the nuclear marker Hoechst. 1095 Scale bars, $50 \mu \mathrm{m}$.

1096 (C) Proteomics strategy to identify AnkR-interacting proteins. PSM, peptide spectral match. 1097 (D, E) Immunostaining of cortex (D) and hippocampus (E) using antibodies against AnkR (red) 1098 and $\mathrm{NrCAM}$ (green). Arrowheads in (E) indicate $\mathrm{AnkR}^{+} / \mathrm{NrCAM}^{+}$neurons. Scalebars, $20 \mu \mathrm{m}$ (D), $109950 \mu \mathrm{m}(\mathrm{E})$.

1100 (F) Immunofluorescence of hippocampus using fluorescent WFA (red) and antibodies against 1101 NrCAM (green). Arrowheads indicate WFA ${ }^{+}$neurons. Scalebar, $25 \mu \mathrm{m}$.

1102 (G, H) Immunostaining of caudoputamen in control and AnkR-deficient mouse brain using 1103 fluorescent WFA (red) and antibodies against NrCAM (green). Arrowheads indicate WFA ${ }^{+}$ 1104 neurons. Scalebars, $50 \mu \mathrm{m}$.

1105 (I) Staining of deep cerebellar nuclei using antibodies against Nrp1 (green) and AnkR (red). 1106 Scalebar, $100 \mu \mathrm{m}$. 
bioRxiv preprint doi: https://doi.org/10.1101/2021.01.21.427626; this version posted January 21, 2021. The copyright holder for this preprint (which was not certified by peer review) is the author/funder, who has granted bioRxiv a license to display the preprint in perpetuity. It is made available under aCC-BY 4.0 International license.

\section{Figure 3}
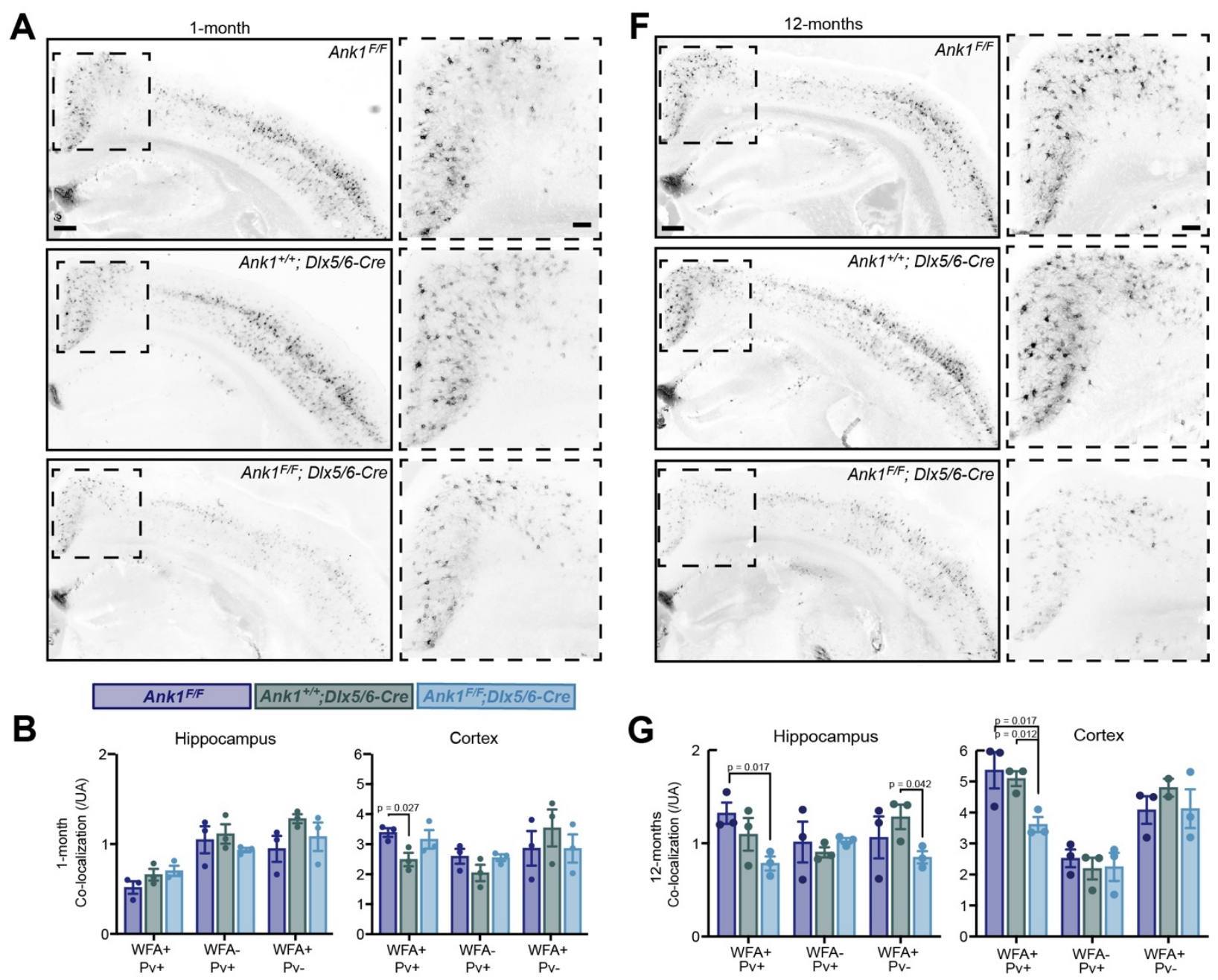

G
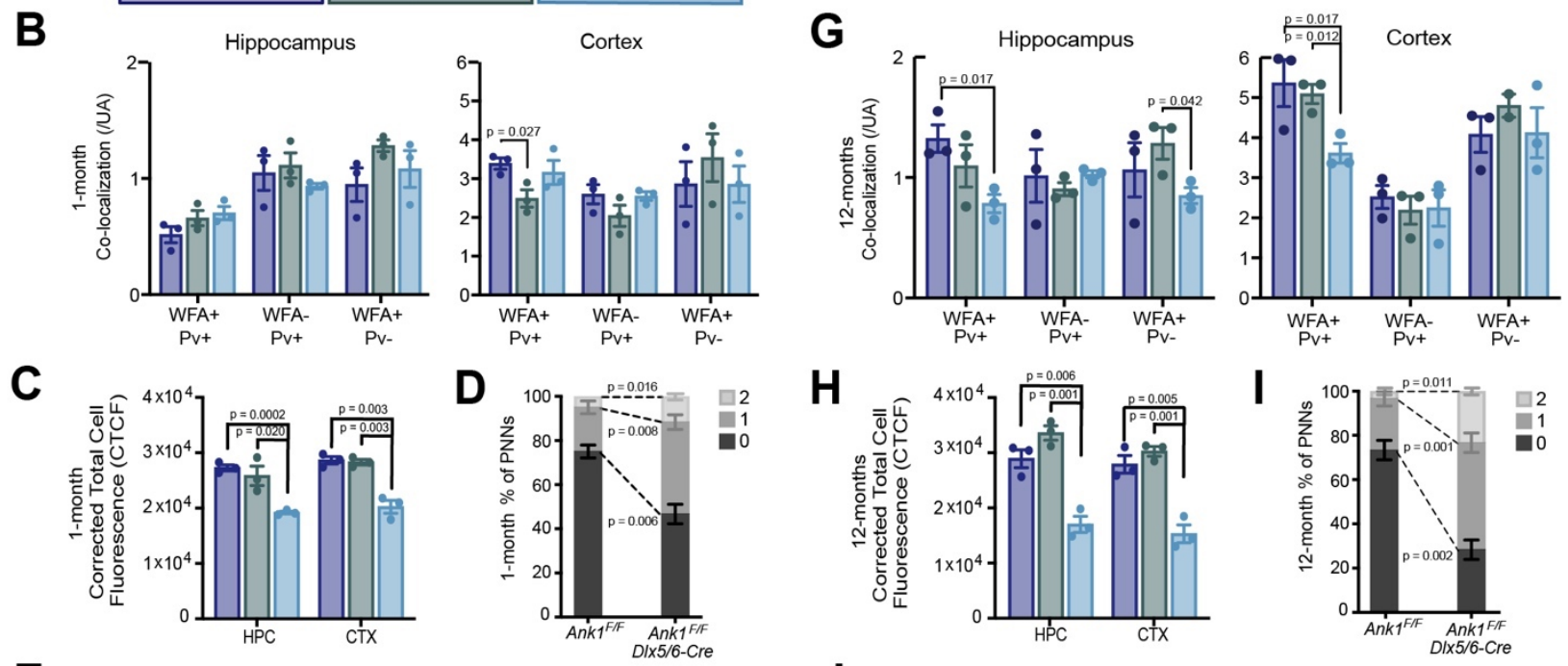

H
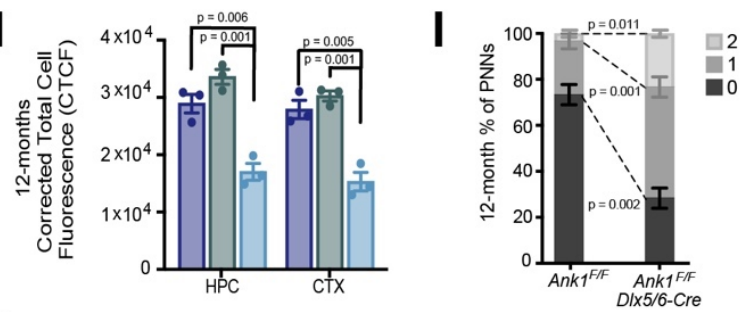

E
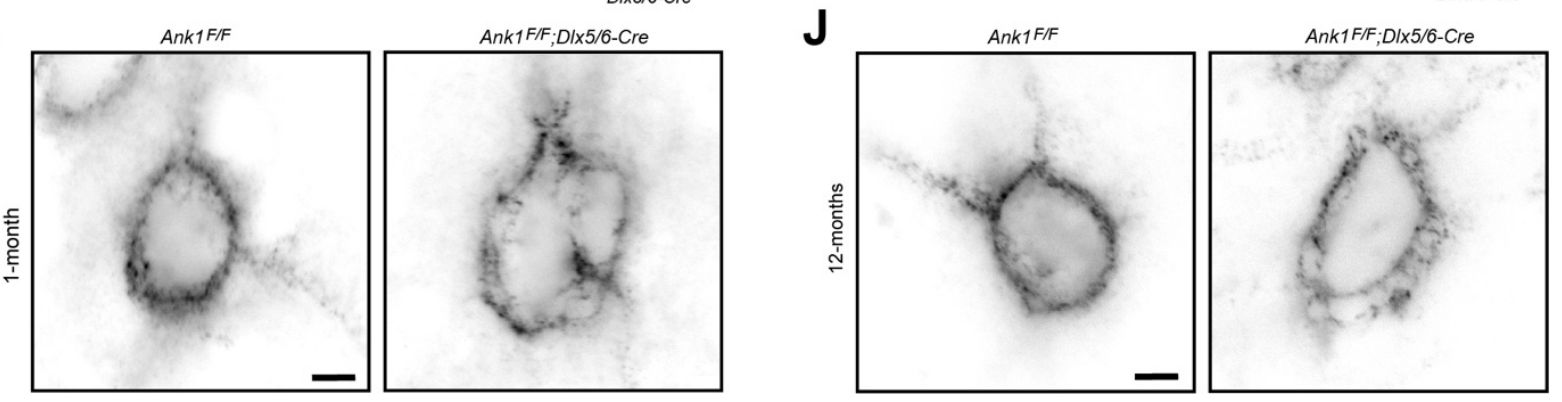
1110 Figure 3. AnkR maintains perineuronal net density and structure.

1111 (A) Fluorescent WFA labeling of PNNs in coronal sections of cortex and hippocampus in one-

1112 month-old mice. Genotypes of the respective mice are indicated. Boxed regions are shown to 1113 the right. Scalebars, $250 \mu \mathrm{m}$ and $100 \mu \mathrm{m}$.

1114 (B) Quantification of colocalization between WFA and Pv labeling per unit area (UA) in 1115 hippocampus and cortex. $\mathrm{N}=3$ mice/group.

1116 (C) Corrected total cell fluorescence (CTCF) in hippocampus (HPC) and cortex (CTX). N=3

1117 mice/group, $\mathrm{n}=230$ cells/animal.

1118 (D) Semi-quantitative analysis of high magnification WFA showing increased hole size and

1119 disruption of PNNs in retrosplenial (RSP) cortex of 1-month mice. $\mathrm{N}=3$ mice/group, $\mathrm{n}=20$

1120 cells/animal.

1121 (E) Fluorescent WFA label of PNNs in RSP cortex of one-month-old mice. Genotypes of the 1122 respective mice are indicated. Scalebars, $5 \mu \mathrm{m}$.

1123 (F) Fluorescent WFA labeling of PNNs in coronal sections of cortex and hippocampus in 12-

1124 month-old mice. Genotypes of the respective mice are indicated. Boxed regions are shown to 1125 the right. Scalebars, $250 \mu \mathrm{m}$ and $100 \mu \mathrm{m}$.

1126 (G) Quantification of colocalization between WFA and Pv labeling per unit area (UA) in 1127 hippocampus and cortex. $\mathrm{N}=3$ mice/group.

1128 (H) CTCF in HPC and CTX. $\mathrm{N}=3$ mice/group, $\mathrm{n}=230$ cells/animal.

1129 (I) Semi-quantitative analysis of high magnification WFA showing increased hole size and 1130 disruption of PNNs in RSP cortex of 12-month mice. $\mathrm{N}=3$ mice/group, $\mathrm{n}=20$ cells/animal.

1131 (J) Fluorescent WFA label of PNNs in RSP cortex of 12-month-old mice. Genotypes of the 1132 respective mice are indicated. Scalebars, $5 \mu \mathrm{m}$. Error bars indicate mean $\pm \mathrm{SEM}$. N=3/group. 


\section{Supplemental Figure 3}

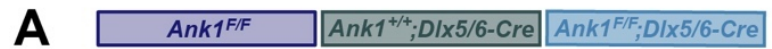

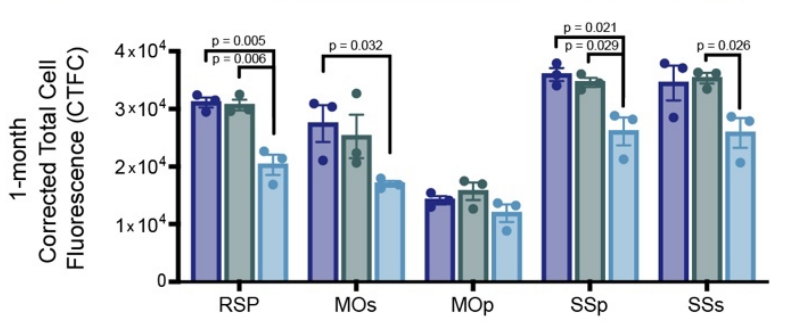

B

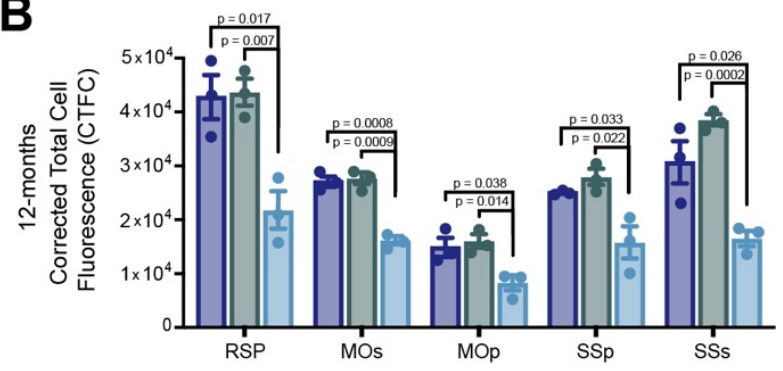

C

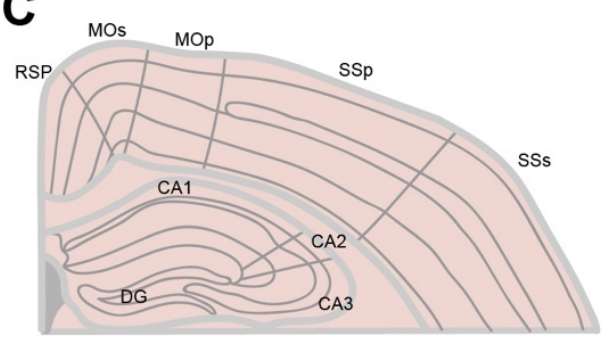

D

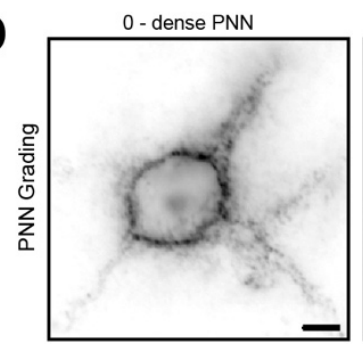

1 - few small holes

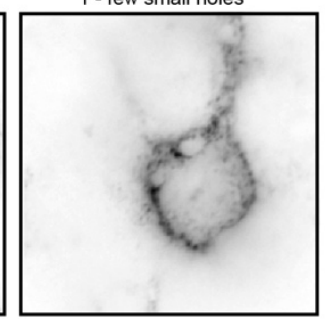

2 - large numerous holes

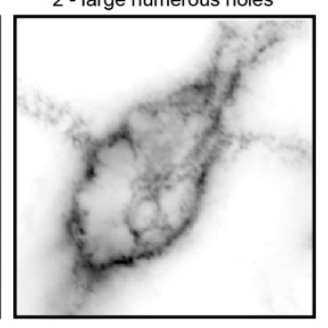

1134

1135

1136

1137

1138

1139

1140

1141

1142

1143

Supplemental Figure 3. WFA labeling is reduced across cortical regions. (A, B) Corrected Total Cell Fluorescence (CTCF) across cortical regions at one- and 12-months of age. RSP, retrosplenial cortex; MOp, primary motor cortex; MOs, secondary motor cortex; SSp, primary somatosensory cortex; SSs, secondary somatosensory cortex. Error bars indicate mean \pm SEM. $\mathrm{N}=3$ /group.

(C) Schematic of cortical regions where CTCF was measured.

(D) WFA labeling of PNNs showing grading scale used for analysis in Figures $3 \mathrm{~d}$ and 3i. Scalebar, $5 \mu \mathrm{m}$. 
bioRxiv preprint doi: https://doi.org/10.1101/2021.0121.427626; this version posted January 21, 2021. The copyright holder for this preprint (which was not certified by peer review) is the author/funder, who has granted bioRxiv a license to display the preprint in perpetuity. It is made available under aCC-BY 4.0 International license.
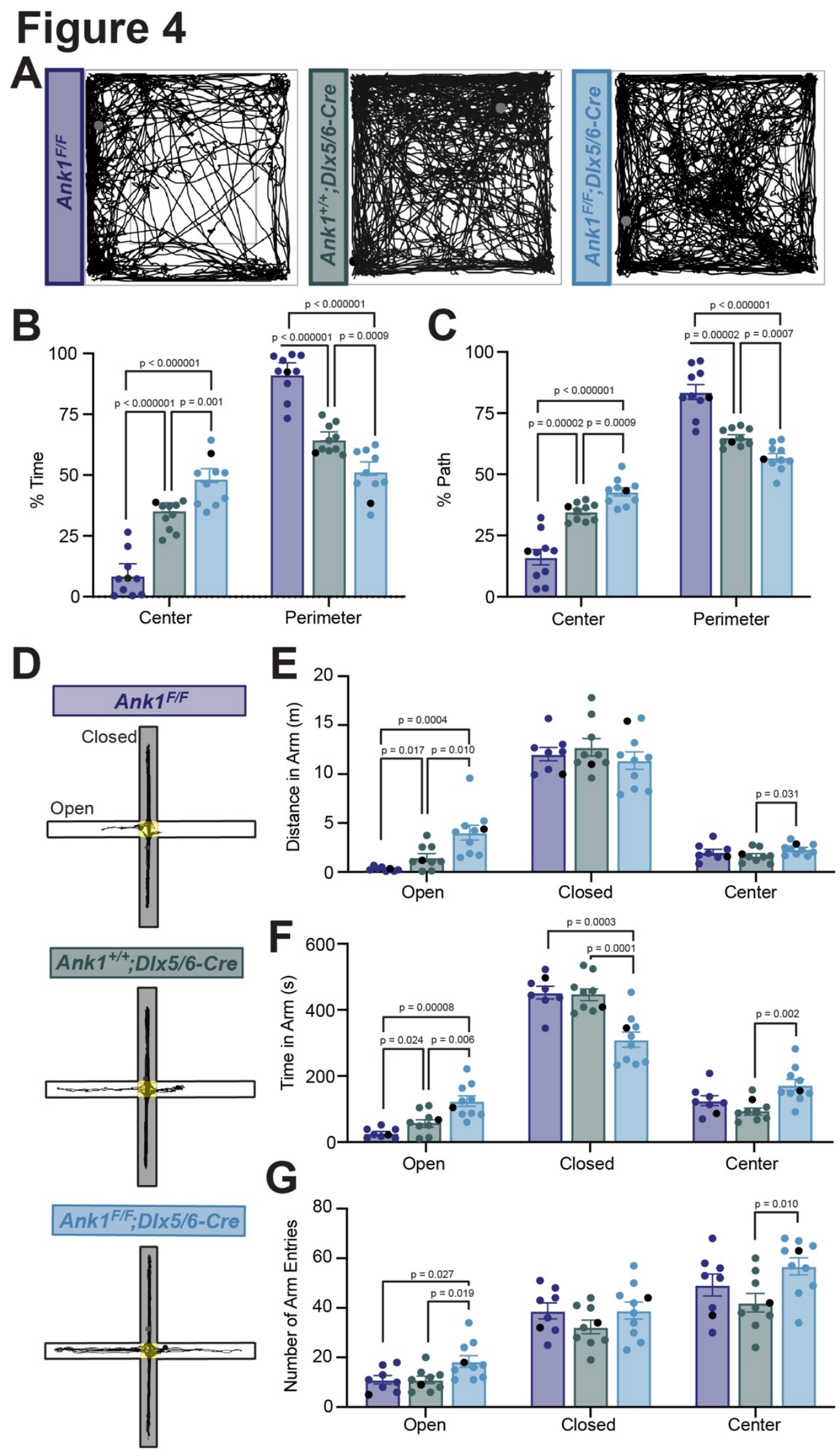
1145 Figure 4. Mice lacking AnkR in GABAergic forebrain interneurons have reduced anxiety.

1146 (A) 30 minute-long recordings of mouse trajectories in the open field assay. Genotypes are

1147 indicated.

1148 (B) The percent of time spent in the center or perimeter of the open field.

1149 (C) The percent of the total path spent in the center or perimeter of the open field.

1150 (D) 10 minute long recordings of mouse trajectories in the elevated plus maze.

1151 (E) The distance traveled in the open arm, closed arm, or the center of the elevated plus maze.

1152 (F) The time spent in the open arm, closed arm, or the center of the elevated plus maze.

1153 (G) The number of entries into the open arm, closed arm, or center of the elevated plus maze.

1154 In all panels error bars indicate mean \pm SEM. Black circles indicate the animals corresponding

1155 to the representative traces. 


\section{Supplemental Figure 4}
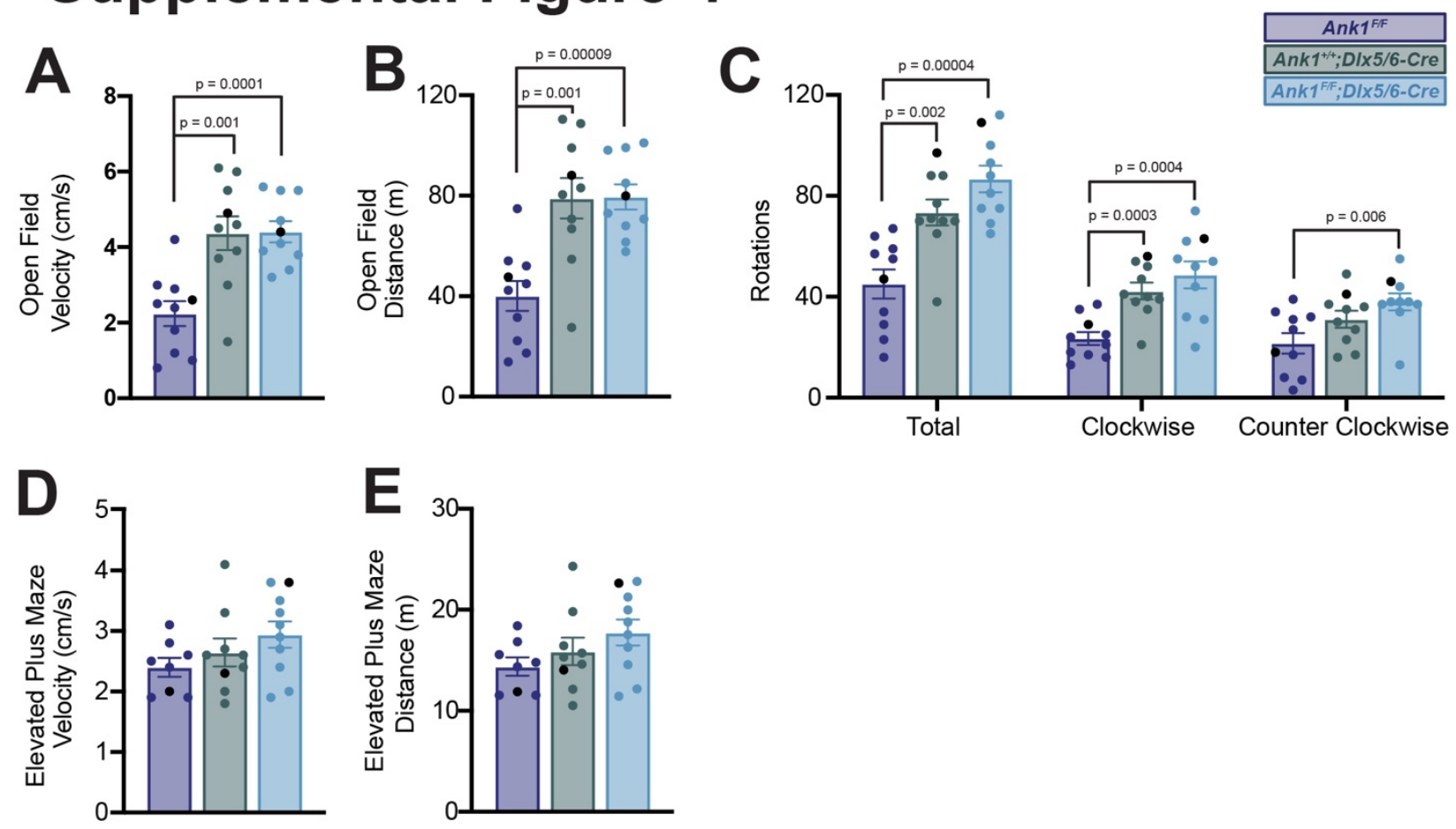

Supplemental Figure 4. Quantification of open field and elevated plus maze assays. $(\mathbf{A}-\mathbf{C})$ Measurements of velocity (A), distance traveled (B), and rotations $(\mathbf{C})$ in the open field test. panels error bars indicate mean \pm SEM. Black circles indicate the animals corresponding to the representative traces in Figure 4. 
bioRxiv preprint doi: https://doi.org/10.1101/2021.01.21.427626; this version posted January 21, 2021. The copyright holder for this preprint (which was not certified by peer review) is the author/funder, who has granted bioRxiv a license to display the preprint in perpetuity. It is made available under aCC-BY 4.0 International license.

\section{Figure 5}
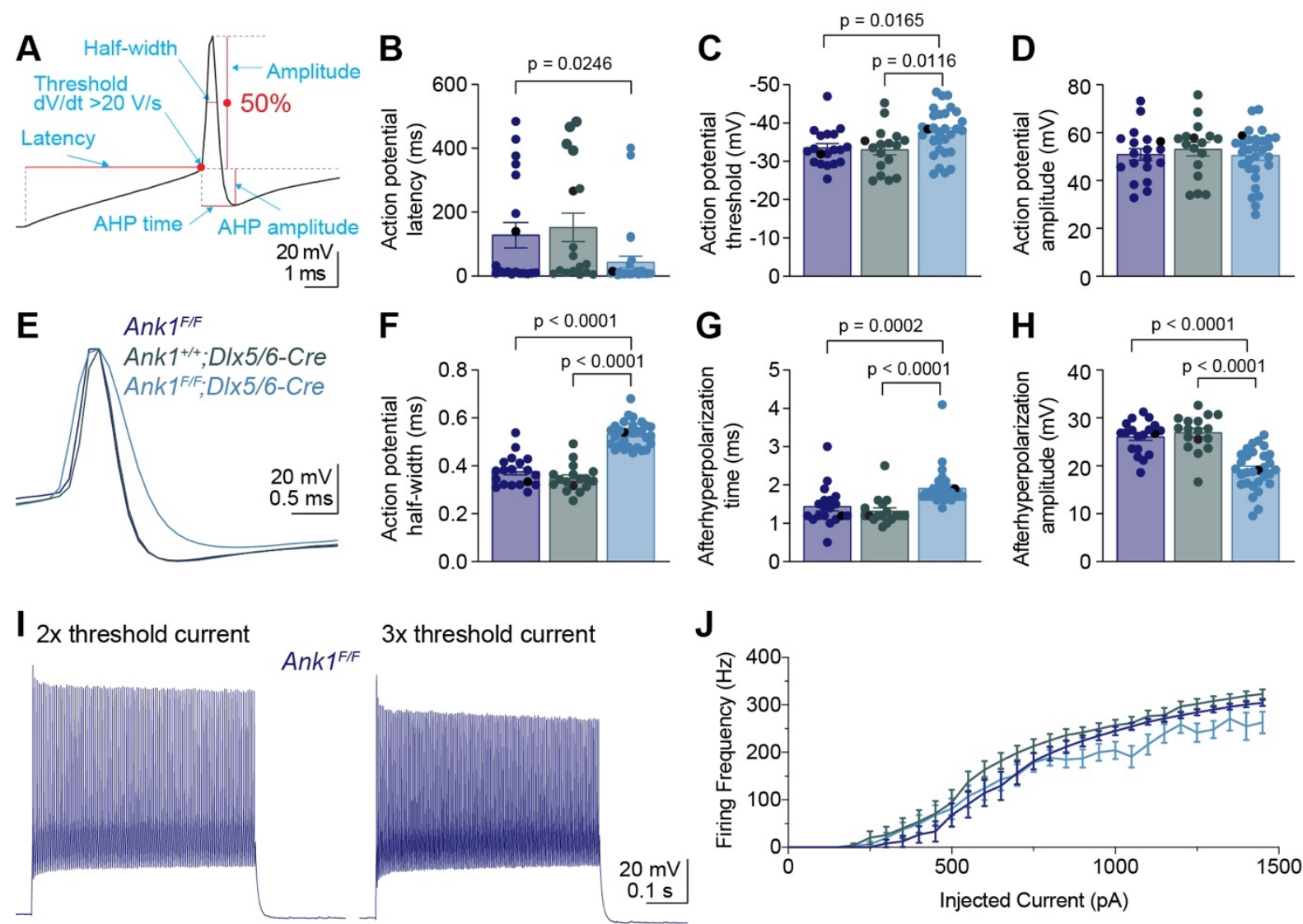

Ank ${ }^{+/+} ; D / \times 5 / 6-C r e$

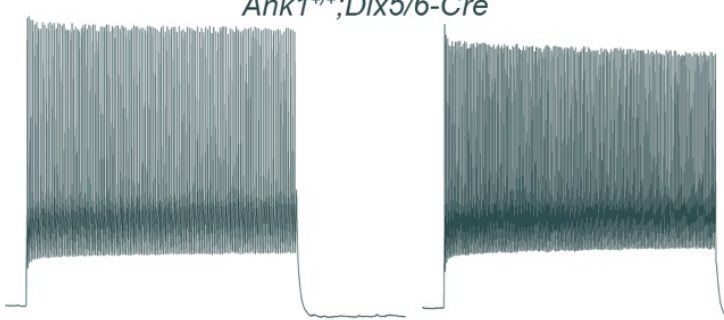

Ank ${ }^{\text {F/F; }}$ D/x5/6-Cre

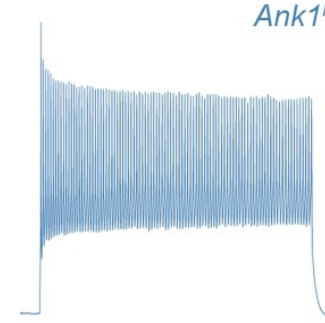

K
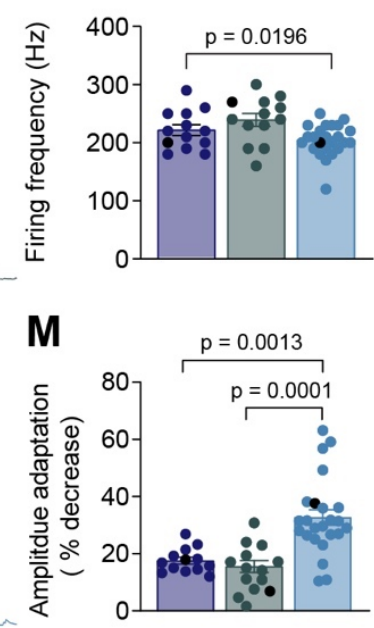

$\mathbf{L}$
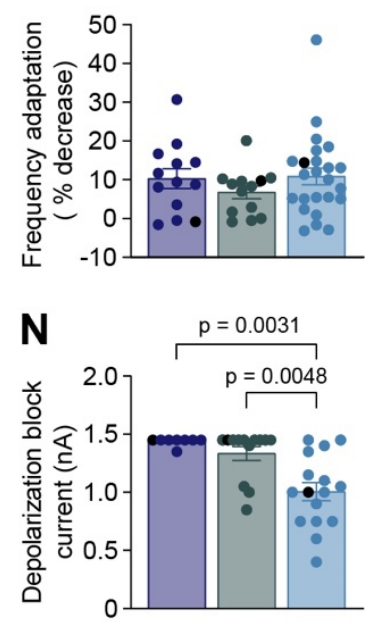
1167 Figure 5. WFA ${ }^{+}$neurons in $A n k 1^{F / F} ; D / x 5 / 6$-Cre mice have abnormal action potentials and spike 1168 train characteristics.

1169 (A) A representative action potential illustrating the measurement of action potential 1170 parameters. AHP, afterhyperpolarization.

1171 (B-D) Summary data showing the action potential latency (B), action potential threshold (C), 1172 and action potential amplitude (D) from the single action potential evoked by rheobase current.

1173 (E) Representative single action potentials evoked by rheobase currents from Ank $1^{\mathrm{F} / \mathrm{F}}$,

$1174 A n k 1^{+/+} ; D / \times 5 / 6-C r e$, and Ank1 ${ }^{F / F} ; D / \times 5 / 6-C r e$ cells. Action potentials are aligned at $50 \%$ of the

1175 rising phase on $\mathrm{X}$ axis and peak on $\mathrm{Y}$ axis. Note the wider action potential with shallower and 1176 delayed afterhyperpolarization in Ank1F/F;D/x5/6-Cre cell.

1177 (F-H) Summary data showing the action potential half-width (F), afterhyperpolarization time

1178 (G), and afterhyperpolarization amplitude (H) from the single action potentials evoked by

1179 rheobase currents.

1180 (I) Representative spike trains from Ank1/f/f, Ank1 ${ }^{+/+} ; D / \times 5 / 6-C r e$, and Ank1 ${ }^{\mathrm{F} / F} ; D / \times 5 / 6-C r e$ cells in 1181 response to 500-ms current injection. Left and right traces show the spike trains evoked by 1182 currents that are 2 and 3 times of the action potential threshold currents, respectively. Note 1183 the strong amplitude adaptation and premature depolarization block indicated by the arrow in 1184 the right trace of $A n k 1^{F / F} ; D / \times 5 / 6$-Cre cell.

1185 (J) The average firing frequency during 500-ms current injection as a function of injected 1186 currents. Note, recording was stopped at maximal $1450 \mathrm{pA}$ current or when cells reached 1187 depolarization block. Since 13 out of 15 Ank1 f/f;Dl $55 / 6-C r e+$ cells reached depolarization block 1188 prior to $1450 \mathrm{pA}$ current while only 3 out of 19 control cells reached depolarization block prior to $1450 \mathrm{pA}$, the firing frequency is overestimated in the high current range for $A n k 1^{\mathrm{F} / \mathrm{F}} ; \mathrm{D} / \mathrm{X} 5 / 6$ Cre neurons. frequency adaptation (L), and amplitude adaptation (M) from the spike trains evoked by currents that are 2 times of the action potential threshold currents. (N) Summary data showing the minimal currents that caused the cells to enter depolarization block. If the maximal injected current (1450 pA) did not cause depolarization block, then 1450 pA was recorded as the result. For all panels, each circle represents one neuron and the black circles indicate the representative cells in ( $E$ and $\mathrm{I}$ ). Bar graphs represent mean \pm SEM. Statistical significance was determined by one-way ANOVA or Kruskal-Wallis test with multiple 1199 comparisons. 
bioRxiv preprint doi: https://doi.org/10.1101/2021.01.21.427626; this version posted January 21, 2021. The copyright holder for this preprint (which was not certified by peer review) is the author/funder, who has granted bioRxiv a license to display the preprint in perpetuity. It is made available under aCC-BY 4.0 International license.

\section{Supplemental Figure 5}
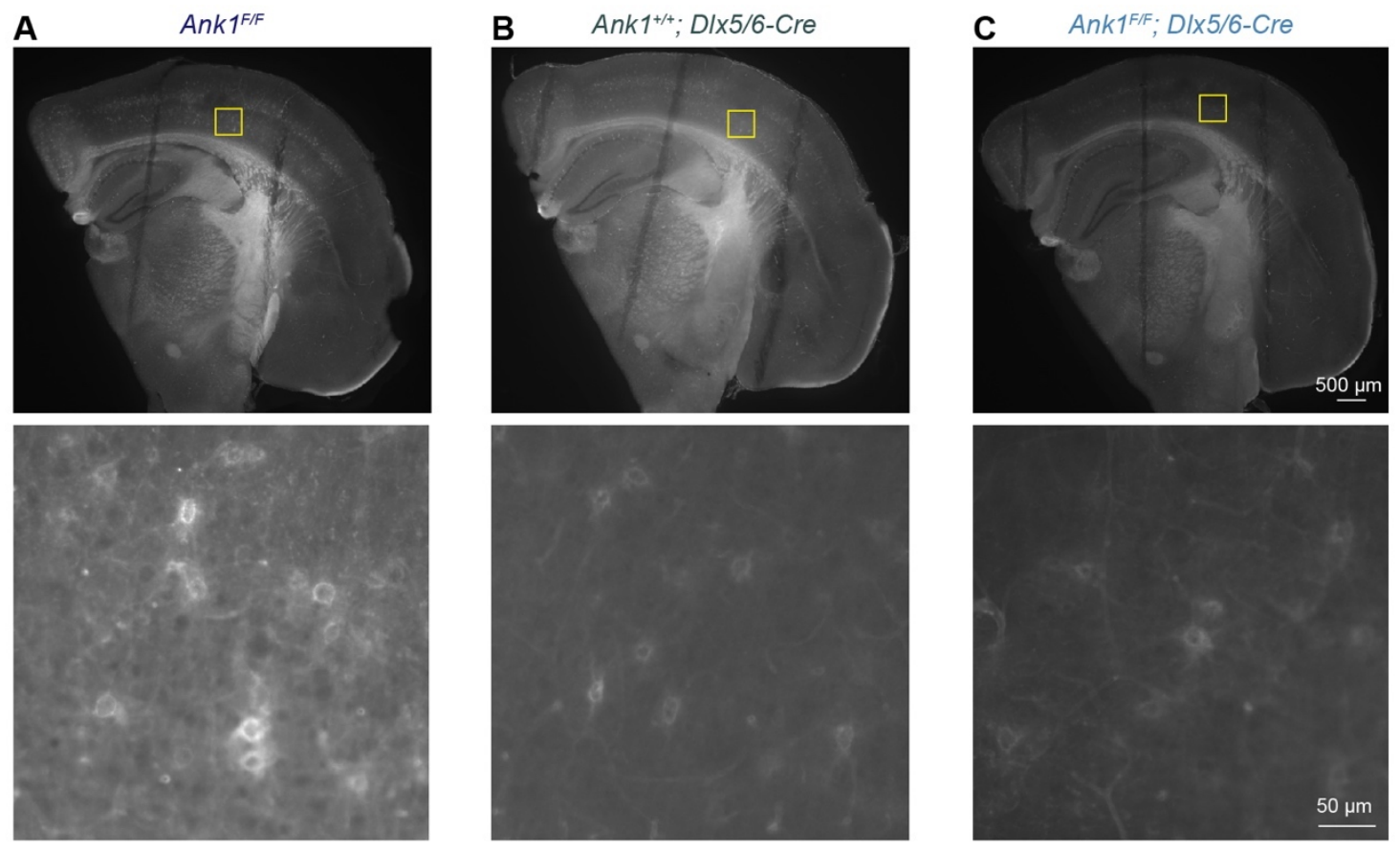

D

Ank1F/F
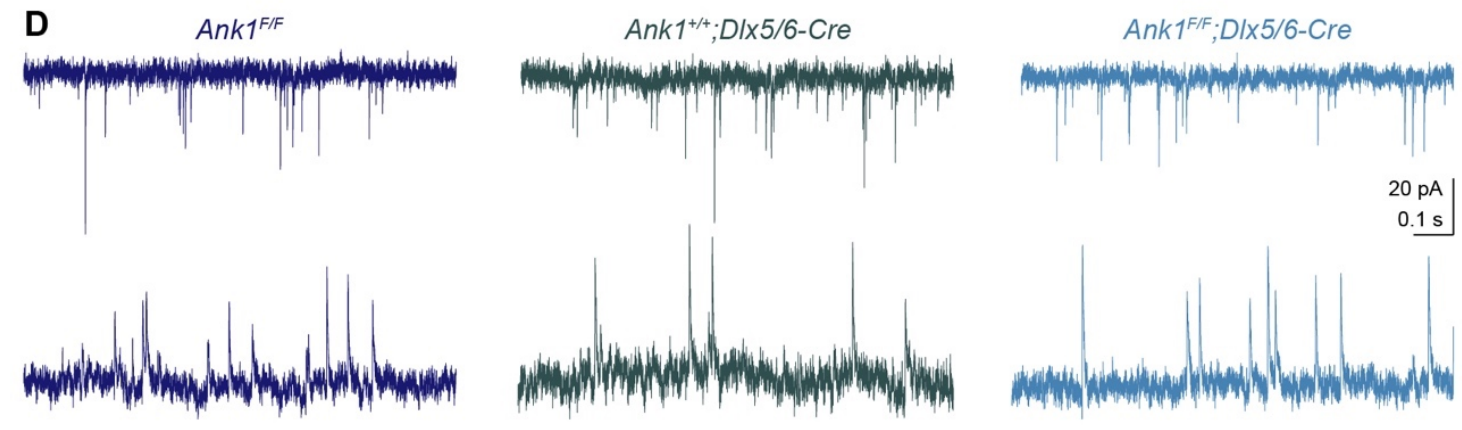

\section{G}
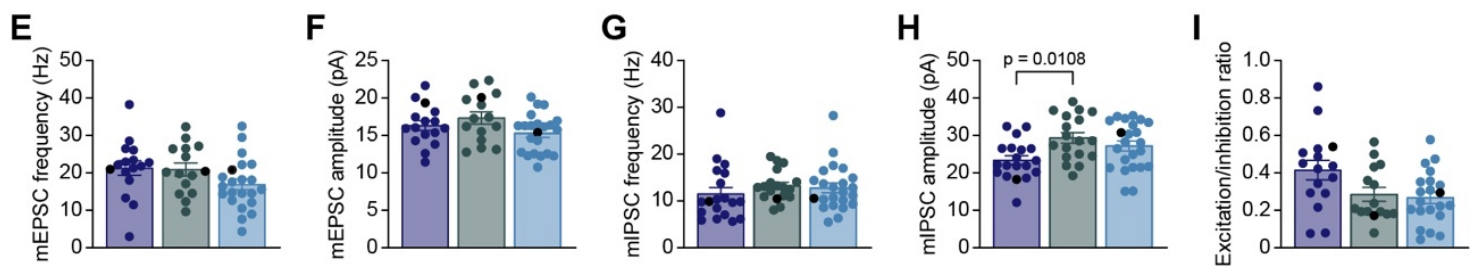
1203 Supplemental Figure 5. Flourescein-WFA labeling of perineuronal nets in live slices for 1204 electrophysiology.

1205 (A) Top: low magnification image of a coronal slice from the left hemisphere of an Ank $1^{f / f}$ 1206 mouse after recording. Lines on the brain slice are the indentations resulted from the mesh 1207 used to hold the slice in place during recording. Bottom: high magnification image of the somatosensory cortex layer 5 within the boxed region in the low magnification image where 1209 recording was performed.

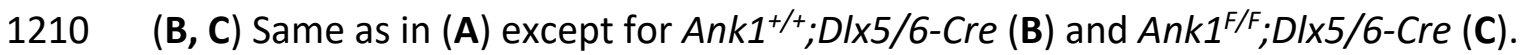

1211 (D) Representative traces of miniature excitatory postsynaptic currents (mEPSCs) recorded at $121270 \mathrm{mV}$ (top) and miniature inhibitory postsynaptic currents (mIPSCs) recorded at $+10 \mathrm{mV}$

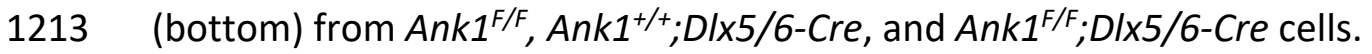

1214 (E, F) Summary data of mEPSC frequency (E) and amplitude (F).

1215 (G, H) Summary data of mIPSC frequency (G) and amplitude (H).

1216 (I) Summary data of excitation/inhibition ratio that is the ratio between the integrated mEPSC 1217 charge per unit time and integrated mIPSC charge per unit time.

1218 Each circle represents one neuron and the black circles indicate the representative cells in (D). 1219 Error bars indicate mean \pm SEM. Statistical significance was determined by one-way ANOVA or Kruskal-Wallis test with multiple comparisons. 
bioRxiv preprint doi: https://doi.org/10.1101/2021.0121.427626; this version posted January 21, 2021. The copyright holder for this preprint (which was not certified by peer review) is the author/funder, who has granted bioRxiv a license to display the preprint in perpetuity. It is made available under aCC-BY 4.0 International license.

\section{Figure 6}

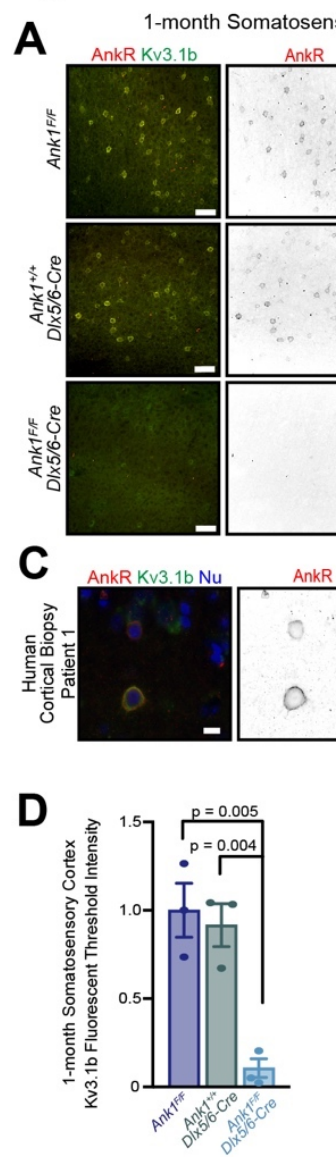

\section{B}

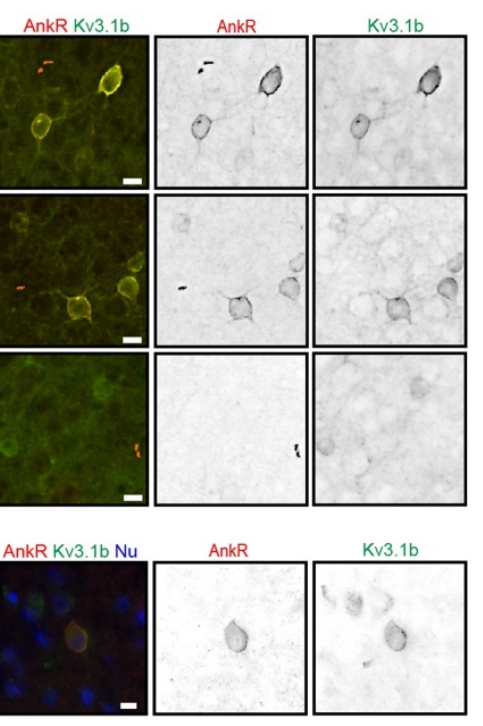

E
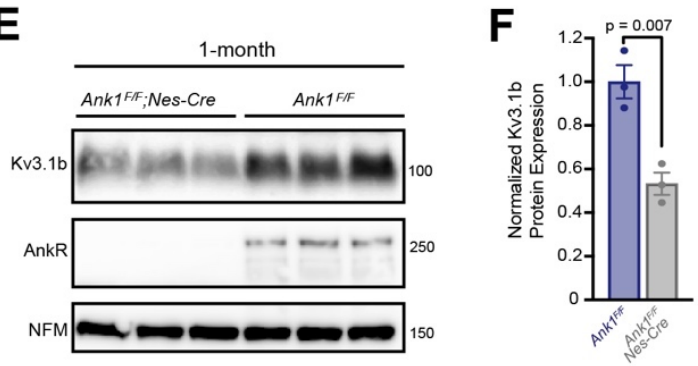

G
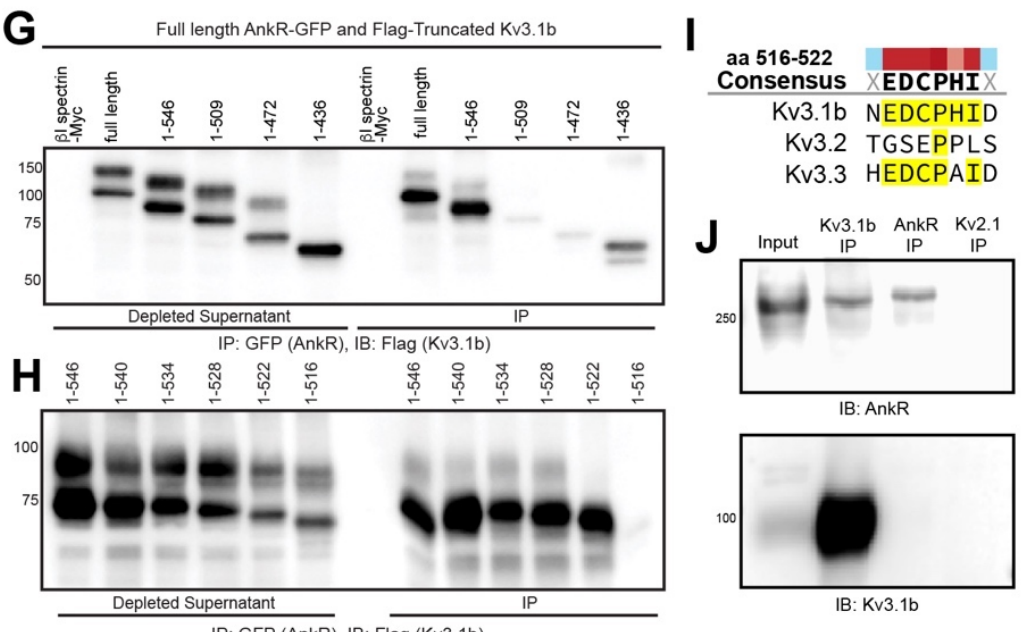

IP: GFP (AnkR), IB: Flag (Kv3.1b)
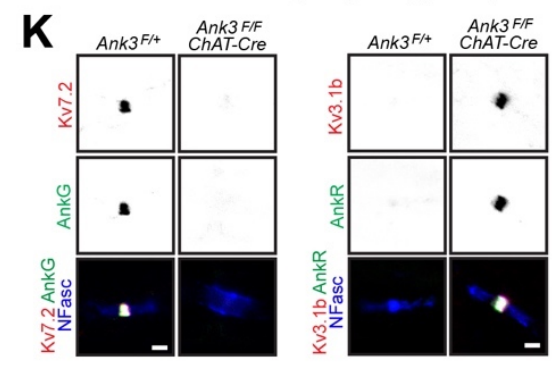

L $\quad$ @Kv7.2 OKv3.1b $\bullet$ AnkG OAnkR

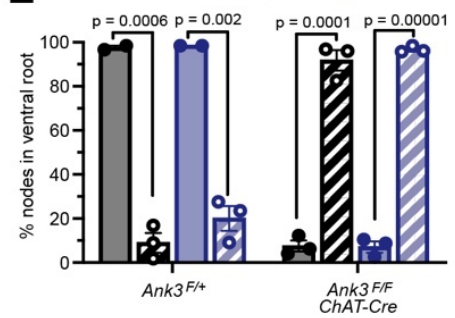


1223 Figure 6. AnkR binds to $\mathrm{Kv} 3.1 \mathrm{~b} \mathrm{~K} \mathrm{~K}^{+}$channels and is both necessary and sufficient for its 1224 membrane localization and clustering.

1225 (A, B) Immunostaining of 1-month-old somatosensory cortex for AnkR (red) and Kv3.1b (green).

1226 Low magnification images are shown in (A) and high magnification images in (B). The

1227 genotypes analyzed are shown. Scalebars, $50 \mu \mathrm{m}$ in (A) and $10 \mu \mathrm{m}$ in (B).

1228 (C) Immunostaining of human cortical biopsies from two separate patients using antibodies

1229 against AnkR (red) and Kv3.1b (green), and DAPI (blue) to label nuclei (Nu). Scalebars, $10 \mu \mathrm{m}$.

1230 (D) Quantification of Kv3.1b immunofluorescence intensity in control and Ank1 $1^{F / F}$;D/x5/6-Cre

1231 mice.

1232 (E) Immunoblots of brain homogenates from 3 one-month-old control and 3 one-month-old

1233 AnkR-deficient brains using antibodies against Kv3.1b, AnkR, and NFM.

1234 (F) Quantification of Kv3.1b protein normalized to NFM.

1235 (G, H). Immunoblots of AnkR-GFP immunoprecipitations in cells co-expressing AnkR-GFP with

1236 Myc-tagged $\beta 1$ spectrin, full length Flag-tagged Kv3.1b, or truncated versions of Flag-tagged

1237 Kv3.1b. The amino acids included in the Flag-tagged Kv3.1b truncation mutants are indicated.

1238 (I) The consensus AnkR-binding motif present in Kv3.1b and Kv3.3, but not Kv3.2.

1239 (J) Immunoblots of Kv3.1b, AnkR, and Kv2.1 immunoprecipitation reactions using antibodies

1240 against AnkR and Kv3.1b.

1241 (K) Immunostaining of ventral root nodes of Ranvier in Ank $3^{\mathrm{F} /+}$ and $A n k 3^{\mathrm{F} / \mathrm{F}}$;ChAT-Cre mice using

1242 antibodies against AnkG (green), Kv7.2 (red), and neurofascin (NFasc, blue) on the left, and

1243 AnkR (green), Kv3.1b (red), and NFasc (blue) on the right. Scalebars, $1 \mu \mathrm{m}$.

1244 (L) Quantification of the percentage of nodes of Ranvier labeled for Kv7.2, Kv3.1b, AnkG, and

1245 AnkR in $A n k 3^{F /+}$ and $A n k 3^{F / F} ; C h A T$-Cre mice. 60-116 nodes/group. Error bars indicate mean \pm

1246 SEM. 


\section{Supplemental Figure 6}

A 12-month Somatosensory Cortex

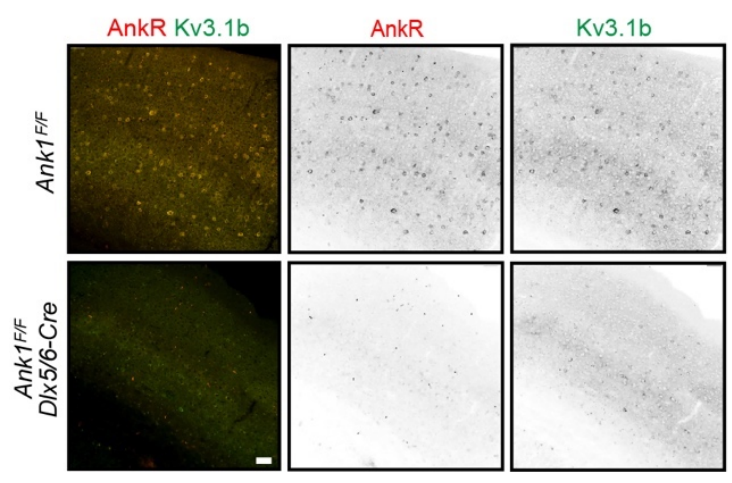

D

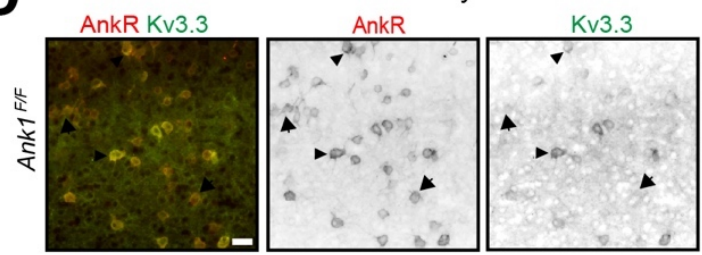

G
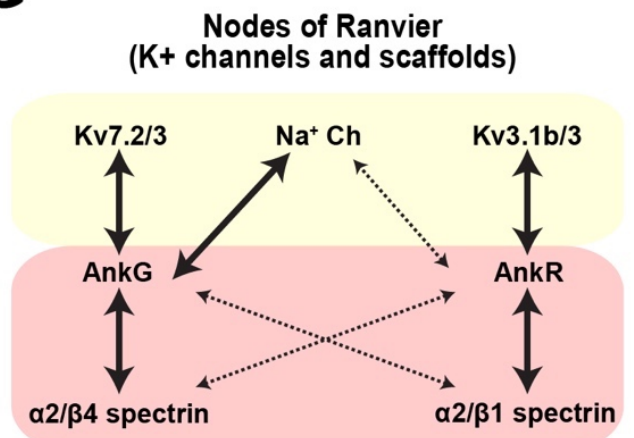

B
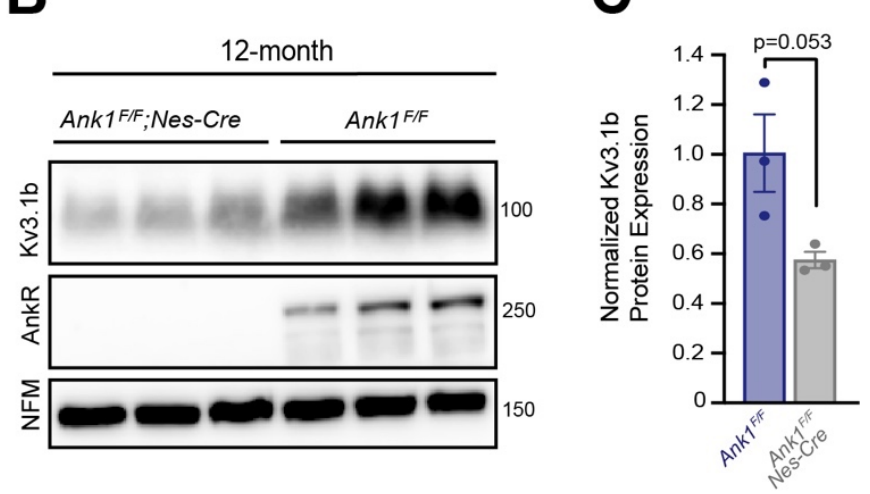

E
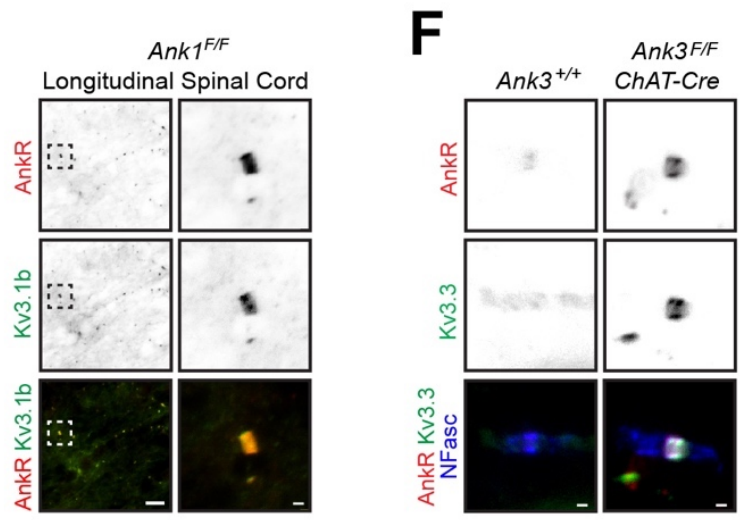

Supplemental Figure 6. Kv3.1b membrane localization requires AnkR.

(A) Immunolabeling of 12 -month-old somatosensory cortex from Ank1/F and Ank1 ${ }^{F / F} ; D / \times 5 / 6$ Cre mice using antibodies against AnkR (red) and Kv3.1b (green). Scalebar, $50 \mu \mathrm{m}$. old AnkR-deficient brains using antibodies against Kv3.1b, AnkR, and NFM.

(D) Immunolabeling of 1-month-old somatosensory cortex from Ank1 $1^{\mathrm{F} / \mathrm{F}}$ mice using antibodies against AnkR (red) and Kv3.3 (green). Scalebar, $25 \mu \mathrm{m}$. (green). Scalebars, $10 \mu \mathrm{m}$ and $1 \mu \mathrm{m}$.

1258 (F) Immunostaining of ventral root nodes of Ranvier in $A n k 3^{+/+}$and Ank $3^{F / F}$;ChAT-Cre mice using antibodies against AnkR (red), Kv3.3 (green), and NFasc (blue). Scalebar, $1 \mu \mathrm{m}$. scaffold to which they bind. 


\section{Figure 7}
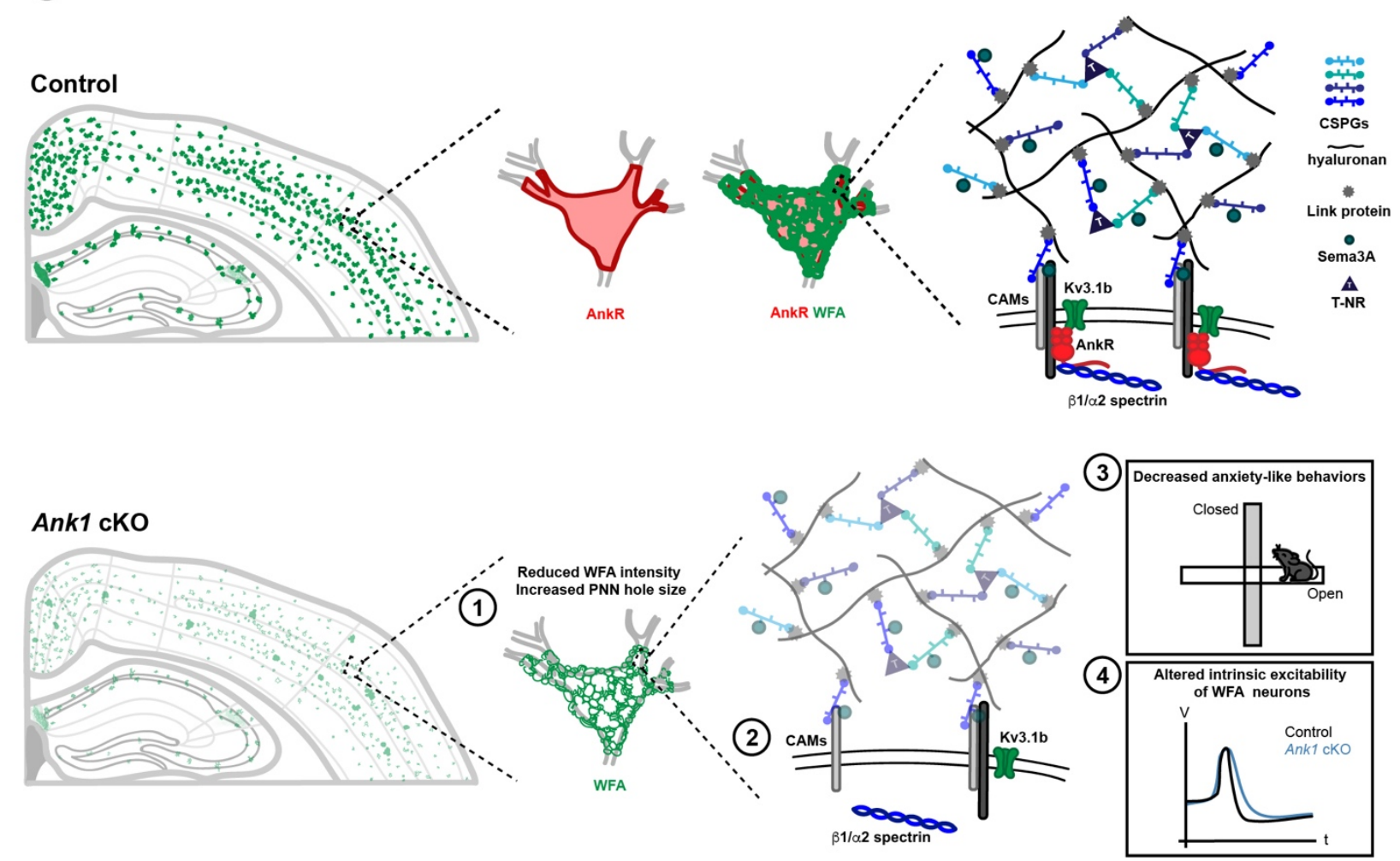

Figure 7. AnkR is highly expressed in the somatodendritic domain of $\mathrm{Pv}^{+}$interneurons which are surrounded by PNNs, a specialized ECM structure. AnkR is a scaffolding protein that binds to and stabilizes PNN-associated CAMs (including NrCAM and PlexinA4) and ion channels (including Kv3.1b) by linking them to the $\beta 1-\alpha 2$ spectrin-based cytoskeleton. Loss of AnkR results in 1) altered PNN morphology including reduced WFA intensity and decreased compactness of the nets; 2 ) molecular changes including reduced $\beta 1$ spectrin, PNN-associated NrCAM, and Kv3.1b; 3) behavioral changes including decreased anxiety-like behaviors in the open field and elevated plus maze; and 4) electrophysiological changes including decreased AP latency and threshold, broader APs with shallower and delayed AHP, and decreased firing rate during current injection. 
Supplemental Table 1.

p value (One-Way ANOVA or Kruskal-Wallis test)

\begin{tabular}{|c|c|c|c|c|c|c|}
\hline & $A n k 1^{F / F}$ & $\begin{array}{c}\text { Ank1 } 1^{+/+} ; \\
\text {Dlx5/6-Cre }\end{array}$ & $\begin{array}{c}\text { Ank1 }{ }^{F / F} ; \\
\text { Dlx5/6-Cre }\end{array}$ & $\begin{array}{c}\text { Ank1 } 1^{F / F} \\
\text { vs. } \\
\text { Ank1 } \\
\text { Dlx5/6-Cre }\end{array}$ & $\begin{array}{c}\text { Ank1 } \\
\text { vs.F } \\
\text { Ank1 } \\
\text { DlF5 } \\
\text { Dl6-Cre }\end{array}$ & $\begin{array}{c}\text { Ank1/++; } \\
\text { Dlx5/6-Cre } \\
\text { vs. } \\
\text { Ank1 }{ }^{F / F} ; \\
\text { Dlx5/6-Cre }\end{array}$ \\
\hline $\begin{array}{l}\text { Resting membrane } \\
\text { potential }(\mathrm{mV})\end{array}$ & $\begin{array}{c}-66.69 \pm \\
1.373(19)\end{array}$ & $\begin{array}{c}-70.42 \pm \\
0.934(17)\end{array}$ & $\begin{array}{c}-68.8 \pm \\
1.102(30)\end{array}$ & 0.1176 & 0.403 & 0.6037 \\
\hline Input resistance (M $\Omega$ ) & $\begin{array}{c}109 \pm \\
10.56(19)\end{array}$ & $\begin{array}{c}131.7 \pm \\
15.94(17)\end{array}$ & $\begin{array}{c}129.6 \pm \\
7.544(30)\end{array}$ & 0.6384 & 0.1419 & $>0.9999$ \\
\hline $\begin{array}{l}\text { Membrane capacitance } \\
\qquad(\mathrm{pF})\end{array}$ & $\begin{array}{c}82.27 \pm \\
4.849(19)\end{array}$ & $\begin{array}{c}81.85 \pm \\
25.74(17)\end{array}$ & $\begin{array}{c}67.17 \pm \\
4.068(30)\end{array}$ & 0.9983 & 0.0708 & 0.0956 \\
\hline Rheobase current (pA) & $\begin{array}{c}307.1 \pm \\
24.56(19)\end{array}$ & $\begin{array}{c}315.9 \pm \\
26.85(17)\end{array}$ & $\begin{array}{c}300.5 \pm \\
17.75(30)\end{array}$ & 0.9652 & 0.9743 & 0.8768 \\
\hline $\begin{array}{l}\text { Action potential latency } \\
\qquad(\mathrm{ms})\end{array}$ & $\begin{array}{c}128 \pm \\
39.41(19)\end{array}$ & $\begin{array}{c}152.2 \pm \\
44.77(17)\end{array}$ & $\begin{array}{c}43.71 \pm \\
18.01(30)\end{array}$ & $>0.9999$ & 0.0973 & 0.0246 \\
\hline $\begin{array}{l}\text { Action potential } \\
\text { threshold (mV) }\end{array}$ & $\begin{array}{c}-33.51 \pm \\
1.107(19)\end{array}$ & $\begin{array}{c}-33.09 \pm \\
1.416(17)\end{array}$ & $\begin{array}{c}-37.62 \pm \\
1.087(30)\end{array}$ & 0.9766 & 0.0165 & 0.0116 \\
\hline $\begin{array}{l}\text { Action potential } \\
\text { amplitude (mV) }\end{array}$ & $\begin{array}{c}50.88 \pm \\
2.419(19)\end{array}$ & $\begin{array}{c}53.12 \pm \\
2.858(17)\end{array}$ & $\begin{array}{c}50.41 \pm \\
1.965(30)\end{array}$ & 0.8152 & 0.9881 & 0.6962 \\
\hline $\begin{array}{l}\text { Action potential half- } \\
\text { width (ms) }\end{array}$ & $\begin{array}{c}0.3765 \pm \\
0.015(19)\end{array}$ & $\begin{array}{c}0.3486 \pm \\
0.014(17)\end{array}$ & $\begin{array}{c}0.5316 \pm \\
0.001(30)\end{array}$ & 0.3124 & $<0.0001$ & $<0.0001$ \\
\hline $\begin{array}{l}\text { Afterhyperpolarization } \\
\text { amplitude }(\mathrm{mV})\end{array}$ & $\begin{array}{c}26.07 \pm \\
0.773(19)\end{array}$ & $\begin{array}{c}26.9 \pm \\
0.923(17)\end{array}$ & $\begin{array}{c}19.19 \pm \\
0.747(30)\end{array}$ & $>0.9999$ & $<0.0001$ & $<0.0001$ \\
\hline $\begin{array}{c}\text { Afterhyperpolarization } \\
\text { time (ms) }\end{array}$ & $\begin{array}{c}1.442 \pm \\
0.119(19)\end{array}$ & $\begin{array}{c}1.318 \pm \\
0.087(17)\end{array}$ & $\begin{array}{c}1.913 \pm \\
0.088(30)\end{array}$ & 0.9943 & 0.0002 & $<0.0001$ \\
\hline $\begin{array}{c}\text { Spike frequency } \\
\text { adaptation }\end{array}$ & $\begin{array}{c}0.897 \pm \\
0.025(13)\end{array}$ & $\begin{array}{c}0.9326 \pm \\
0.017(13)\end{array}$ & $\begin{array}{c}0.8912 \pm \\
0.022(24)\end{array}$ & 0.9982 & $>0.9999$ & 0.721 \\
\hline $\begin{array}{l}\text { Spike amplitude } \\
\text { adaptation }\end{array}$ & $\begin{array}{c}0.8243 \pm \\
0.012(13)\end{array}$ & $\begin{array}{c}0.8446 \pm \\
0.075(13)\end{array}$ & $\begin{array}{c}0.6731 \pm \\
0.027(24)\end{array}$ & $>0.9999$ & 0.0013 & 0.0001 \\
\hline Firing frequency $(\mathrm{Hz})$ & $\begin{array}{c}221.5 \pm \\
9.257(13)\end{array}$ & $\begin{array}{c}329.2 \pm \\
11.06(13)\end{array}$ & $\begin{array}{c}204.6 \pm \\
5.516(24)\end{array}$ & 0.5423 & 0.6966 & 0.0196 \\
\hline $\begin{array}{c}\text { Depolarization block } \\
\text { current (pA) }\end{array}$ & $\begin{array}{c}1438 \pm \\
12.50(8)\end{array}$ & $\begin{array}{c}1335 \pm \\
59.48(13)\end{array}$ & $\begin{array}{c}1006 \pm \\
77.44(16)\end{array}$ & $>0.9999$ & 0.0031 & 0.0048 \\
\hline
\end{tabular}

1274 Supplemental Table 1. Intrinsic properties of WFA ${\text { cells in } A n k 1^{\mathrm{F} / F}, \text { Ank1 }}^{+/+} ; D / x 5 / 6-C r e$, and $1275 A n k 1^{F / F} ; D / \times 5 / 6$-Cre mice. Data are from 3 Ank1 ${ }^{F / F}, 2$ Ank1 $1^{+/+} ; D / \times 5 / 6-C r e$, and 4 Ank1 ${ }^{F / F} ; D / \times 5 / 6-C r e$ 1276 mice, and are reported as mean \pm SEM (number of cells). Bolded $p$ values indicate significance. 
bioRxiv preprint doi: https://doi.org/10.1101/2021.01.21.427626; this version posted January 21, 2021. The copyright holder for this preprint (which was not certified by peer review) is the author/funder, who has granted bioRxiv a license to display the preprint in perpetuity. It is made available under aCC-BY 4.0 International license.

1279 Supplemental Movie 1. WFA in 12-month Ank1 F/F. Scalebar, $5 \mu \mathrm{m}$.

1281 Supplemental Movie 2. WFA in 12-month Ank1 $1^{F / F} ; D / x 5 / 6-C r e$. Scalebar, $5 \mu \mathrm{m}$.

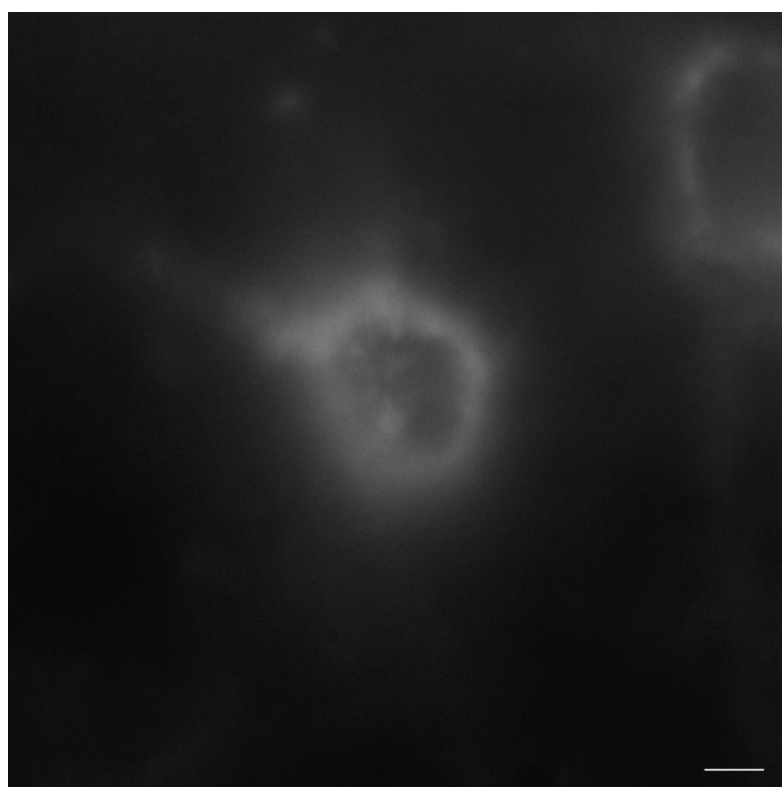

